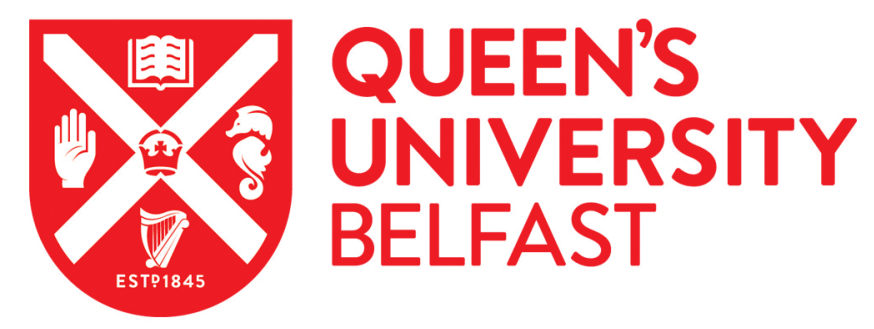

\title{
Identification of damping in a bridge using a moving instrumented vehicle
}

González, A., OBrien, E. J., \& McGetrick, P. J. (2012). Identification of damping in a bridge using a moving instrumented vehicle. Journal of Sound and Vibration, 331(18), 4115-4131.

https://doi.org/10.1016/j.jsv.2012.04.019

Published in:

Journal of Sound and Vibration

Document Version:

Peer reviewed version

Queen's University Belfast - Research Portal:

Link to publication record in Queen's University Belfast Research Portal

Publisher rights

(c) 2012 Elsevier Ltd. This manuscript version is made available under the CC-BY-NC-ND 4.0 license http://creativecommons.org/licenses/by$\mathrm{nc}-\mathrm{nd} / 4.0 /$ which permits distribution and reproduction for non-commercial purposes, provided the author and source are cited.

\section{General rights}

Copyright for the publications made accessible via the Queen's University Belfast Research Portal is retained by the author(s) and / or other copyright owners and it is a condition of accessing these publications that users recognise and abide by the legal requirements associated with these rights.

Take down policy

The Research Portal is Queen's institutional repository that provides access to Queen's research output. Every effort has been made to ensure that content in the Research Portal does not infringe any person's rights, or applicable UK laws. If you discover content in the Research Portal that you believe breaches copyright or violates any law, please contact openaccess@qub.ac.uk. 


\title{
Identification of damping in a bridge using a moving instrumented vehicle
}

\author{
A. González ${ }^{\mathrm{a}, 1}$, E.J. OBrien ${ }^{\mathrm{a}, 2}$ \& P.J. McGetrick ${ }^{\mathrm{a}, 3}$ \\ ${ }^{a}$ School of Civil, Structural \& Environmental Engineering \\ University College Dublin \\ Newstead \\ Belfield \\ Dublin 4 \\ Ireland \\ Phone: ${ }^{1}+353-1-7163219 /^{2}+353-1-7163224 /^{3}+353-1-7163233$ \\ Fax: +353-1-7163297 \\ E-mail: ${ }^{1}$ arturo.gonzalez@ucd.ie, ${ }^{2}$ eugene.obrien@ucd.ie, ${ }^{3}$ mcgetrick@gmail.com
}

\begin{abstract}
In recent years, there has been a significant increase in the number of bridges which are being instrumented and monitored on an ongoing basis. This is in part due to the introduction of bridge management systems designed to provide a high level of protection to the public and early warning if the bridge becomes unsafe. This paper investigates a novel alternative; a low-cost method consisting of the use of a vehicle fitted with accelerometers on its axles to monitor the dynamic behaviour of bridges. A simplified half-car vehicle-bridge interaction model is used in theoretical simulations to test the effectiveness of the approach in identifying the damping ratio of the bridge. The method is tested for a range of bridge spans and vehicle velocities using theoretical simulations and the influences of road roughness, initial vibratory condition of the vehicle, signal noise, modelling errors and frequency matching on the accuracy of the results are investigated.
\end{abstract}

Keywords: bridge, damping, stiffness, vehicle-bridge interaction, damage detection, structural health monitoring. 


\section{Nomenclature}

$\mathbf{C}_{\mathbf{b}} \quad$ damping matrix of bridge model

$C_{i} \quad$ viscous damping coefficient of vehicle axle $i$

$D_{i} \quad$ distance of axle $i$ to $o$

E modulus of elasticity

$\mathbf{f}_{\mathbf{b}} \quad$ forcing vector

$f_{b, 1} \quad 1$ st natural frequency of the bridge

$f_{v, 1} \quad$ body pitch frequency of the vehicle

$f_{v, 2} \quad$ body bounce frequency of the vehicle

$F_{t, i} \quad$ dynamic wheel contact force at wheel $i$

$I_{S} \quad$ sprung mass moment of inertia

$J \quad$ second moment of area

$\mathbf{K}_{\mathbf{b}} \quad$ stiffness matrix of bridge model

$K_{i} \quad$ spring stiffness of vehicle axle $i$

$L \quad$ bridge span length

$m_{s} \quad$ sprung mass

$\mathbf{M}_{\mathbf{b}} \quad$ mass matrix of bridge model

$o \quad$ centre of gravity of vehicle

$P_{i} \quad$ static axle loads of the vehicle

$r_{\text {error }} \quad$ least squares error between road profile estimates

$r_{e s t, i} \quad$ road profile height estimates under wheel $i$

$r_{i} \quad$ road profile displacement under wheel $i$

$R_{i} \quad$ total wheel contact force at wheel $i$

$\mathbf{w}_{\mathbf{b}} \quad$ vector of nodal bridge displacements and rotations 
$\dot{\mathbf{w}}_{\mathbf{b}} \quad$ vector of nodal bridge velocities

$\ddot{\mathbf{w}}_{\mathbf{b}} \quad$ vector of nodal bridge accelerations

$w_{b, i} \quad$ bridge displacement under wheel $i$

$w_{v, i} \quad$ total displacement under wheel $i$

$\dot{w}_{v, i} \quad$ velocity of total displacements under wheel $i$

$y_{s} \quad$ sprung mass bounce displacement

$\dot{y}_{s} \quad$ sprung mass bounce velocity

$\ddot{y}_{s} \quad$ sprung mass bounce acceleration

$\ddot{y}_{s, i} \quad$ acceleration over vehicle axle $i$

$\alpha, \beta \quad$ Rayleigh damping constants

$\theta \quad$ time step parameter for integration

$\theta_{s} \quad$ sprung mass pitch rotation

$\dot{\theta}_{s} \quad$ sprung mass pitch rotational velocity

$\ddot{\theta}_{S} \quad$ sprung mass pitch rotational acceleration

$\mu \quad$ mass per unit length of the bridge

$\xi \quad$ bridge damping ratio

$\xi_{\text {est }} \quad$ bridge damping ratio estimate

$\omega_{1} \quad$ first natural circular frequency of the bridge

$\omega_{2}$ second natural circular frequency of the bridge 


\section{Introduction}

Highway bridge structures form an intrinsic part of road networks. Throughout their lifetime they undergo continuous deterioration due to many factors such as ageing, increased loading and environmental conditions. Maintenance of these structures is essential to provide the required level of safety and service to road users. Increasingly over the last two decades this maintenance has involved the direct instrumentation of bridge structures - commonly referred to as Structural Health Monitoring (SHM) [1-3] - including vibration based monitoring of modal parameters $[4,5]$. The most commonly investigated parameters are natural frequencies and mode shapes due to the relative ease with which they can be measured and interpreted [57]. However, monitoring via direct instrumentation of the bridge can be expensive and time consuming, requiring the installation and maintenance of sensors and data acquisition electronics on the bridge.

Given that a high proportion of highway bridges are reaching or have exceeded their design lives and are not instrumented, some alternative method is needed to detect any change in behaviour of the structure which might be an indicator of some form of damage, e.g. corrosion or cracking. Here a novel low-cost method consisting of the use of a vehicle fitted with accelerometers on its axles is proposed to monitor the dynamic behaviour of bridges. In particular, the method focuses on the identification of the damping of the bridge as it has been shown to be a damage sensitive property [8,9], although it can be easily extended to other bridge parameters, i.e., stiffness, as demonstrated in the paper. The successful implementation of this method would facilitate efficient, widespread monitoring and preliminary screening of existing bridge structures in a transport network while its development would enable maintenance to be programmed in a more cost effective way. A 
preliminary screening of bridge condition based on one or more passes of an instrumented vehicle, could be used to initially target those bridges giving signs of more severe deterioration and to allocate further resources (i.e., through the use of specialised equipment installed on the bridge).

The feasibility of detecting bridge dynamic parameters, such as frequency, from the dynamic response of an instrumented vehicle passing over a bridge has been verified theoretically [1012]. The method proposed by Yang et al [10], which involved an instrumented vehicle acting as a 'message carrier' of the dynamic properties of the bridge, was tested in field trials $[13,14]$. A numerical and experimental study by González et al [15] extended the analysis to a 3-D FEM vehicle-bridge interaction (VBI) model and they concluded that accurate determination of the bridge frequency is only feasible for low velocities and sufficiently high dynamic excitation of the bridge. Experimental investigations have also been conducted to check the feasibility of the approach as part of a drive-by inspection system for bridge monitoring $[11,16,17]$.

Compared to frequencies and mode shapes, damping has been considered to a lesser extent in the field of damage detection and monitoring due to difficulty in quantifying its magnitude [18]. However, recent evidence suggests that damping is quite sensitive to damage in structural elements and in some cases, more sensitive than natural frequencies and mode shapes. Curadelli et al [8] describe an approach, based on a wavelet transform, to detect structural damage by means of the instantaneous damping coefficient identification. They performed experimental tests on a reinforced concrete beam and a six storey 1 bay 3D aluminium frame and numerical simulations of the response of a $2 \mathrm{D}$ reinforced concrete frame with strength and stiffness degradation. The technique is shown to be potentially useful 
as damping is found to be more sensitive to damage than natural frequency in the structures under investigation. In a study on the use of dynamic testing to identify manufacturing defects or structural damage in precast reinforced concrete elements, Modena et al [9] show that the presence of small, visually undetectable cracks cause very little variation in natural frequencies and require higher mode shapes to be detected but they cause considerable changes in damping. They observed damping changes of up to 50\%. In a review of SHM literature from 1996 to 2001, Sohn et al. [19] suggest that crack detection in a structure based on damping has an advantage over detection schemes based on natural frequencies and mode shapes. They point out that damping changes have the ability to detect the nonlinear, dissipative effects that cracks produce. Gutenbrunner et al [20] perform a sensitivity study on damping estimation methods and they note that damping can be used as a damage indicator. In a case study of a single-span post-tensioned concrete bridge crossing a highway near Regau, Austria, they found that the damping ratio of the bridge increased from $1.19 \%$ for the undamaged state to $2.21 \%$ for the damaged state. Kawiecki [21] also comments that damping can be a useful damage sensitive feature. He reaches this conclusion in an investigation of a damage detection method using piezo-elements which can be applied to lightweight and micro-structures. Jeary [22] studies the non-linearity associated with damping in some structures and notes that the damping characteristic is highly indicative of the amount of damage that a structure has undergone during its life.

In general, bridge damping identification techniques have focuses on direct instrumentation of bridges to measure ambient, free or forced vibration. Damping is identified using numerical techniques such as wavelet transforms, the Hilbert transform technique, frequency domain decomposition, empirical mode decomposition and the random decrement technique [23-26]. However, theoretical investigations on the detection of bridge dynamic parameters 
carried out by McGetrick et al [12] and González et al [27] show that it is possible to identify not only bridge frequencies but also changes in the bridge's damping ratio using indirect measurements from an instrumented vehicle. Both conclude that the bridge's frequency of vibration and changes in damping can be identified with ease from the dynamic response of a vehicle for a smooth road profile, while in the presence of a rough road profile the same properties become very difficult to establish. One shortcoming in their approach is their inability to quantify damping in absolute terms, i.e., they only provide changes in damping relative to a previous measurement campaign. The main aim of this paper is to identify the absolute value of the bridge damping ratio from the dynamic response of a vehicle. For this theoretical investigation, a VBI model is created in MATLAB [28]. The vehicle is modelled as a 2-degree-of-freedom half-car and the bridge is modelled as a simply supported finite element (FE) beam. The damping identification procedure consists of a six step computational process which is outlined in Section 3. Simulations are carried out for simply supported bridge spans of 15,25 and 35 metres and vehicle velocities of $10 \mathrm{~m} \mathrm{~s}^{-1}$ to $30 \mathrm{~m} \mathrm{~s}^{-1}$. The influence of road roughness and noise on the results is investigated. The most favourable site conditions are identified in which this method can be used to identify the bridge damping ratio with a reasonable degree of accuracy.

\section{Vehicle-bridge interaction model}

This section describes the vehicle and bridge models used in the iterative VBI procedure employed for this paper. Complex models have been utilised in the literature which incorporate a large number of degrees of freedom to take account of vehicle motions such as body roll or axle hop [29-31] and articulated vehicle configuration [32,33]. A comprehensive review of these and other coupled and uncoupled VBI models in the literature has been 
carried out by González [34]. The VBI model used for the numerical validation of the damping identification algorithm in this paper is similar to that used for a bridge damage identification approach by Kim and Kawatani [35].

\subsection{Vehicle model}

For this investigation, a theoretical half-car model is used to represent the behaviour of the vehicle (Fig. 1). This simple vehicle model has the advantage of being less complex and hence less computationally intensive than many of the models in the literature while it is able to provide measurements for two axles which enables the estimation of displacements under each wheel. Also, while it is a simplified version of a vehicle, its response still illustrates many of the important characteristics of dynamic tyre forces [36]. The model has two independent degrees of freedom which correspond to sprung mass bounce displacement, $y_{s}$ and sprung mass pitch rotation, $\theta_{s}$. The vehicle body and axle component masses are represented by the sprung mass, $m_{s}$. This mass connects to the road surface via a combination of springs of linear stiffness $K_{i}$ and viscous dampers with damping coefficient, $C_{i}$ which represent the combined tyre and suspension components for the front and rear axles $(i=1,2)$.

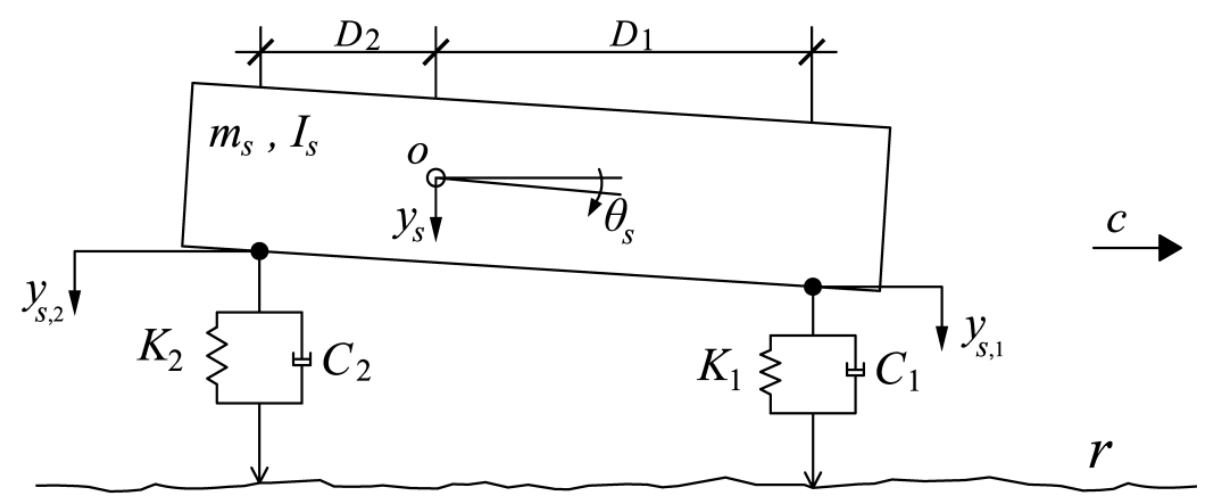

Fig. $1 \quad$ 2-degree-of-freedom half-car model 
Other parameters are the sprung mass moment of inertia, $I_{s}$, and the distance of each axle to the vehicle's centre of gravity $(o)$, i.e., $D_{1}$ and $D_{2}$ in Fig. 1 . The natural frequencies of vibration of the vehicle are $f_{v, 1}=2.39 \mathrm{~Hz}$ and $f_{v, 2}=3.18 \mathrm{~Hz}$ which correspond to body pitch and bounce respectively. The half-car property values are listed in Table 1 and are based on values gathered from the literature $[27,32,36]$.

Table $1 \quad$ Half-car model properties

\begin{tabular}{|c|c|c|c|c|c|c|c|c|}
\hline \multirow{2}{*}{$\begin{array}{l}\text { Property } \\
\text { Symbol }\end{array}$} & \multirow{2}{*}{$\begin{array}{c}\begin{array}{c}\text { Body } \\
\text { mass } \\
(\mathrm{kg})\end{array} \\
m_{s}\end{array}$} & \multicolumn{2}{|c|}{$\begin{array}{c}\text { Distance of axle } \\
\text { to centre of } \\
\text { gravity (m) }\end{array}$} & \multicolumn{2}{|c|}{$\begin{array}{c}\text { Suspension } \\
\text { stiffness }\left(\mathrm{N} \mathrm{m}^{-1}\right)\end{array}$} & \multicolumn{2}{|c|}{$\begin{array}{c}\text { Suspension } \\
\text { damping }\left(\mathrm{N} \mathrm{s} \mathrm{m}^{-1}\right)\end{array}$} & \multirow{2}{*}{$\begin{array}{c}\begin{array}{c}\text { Moment } \\
\text { of inertia } \\
\left(\mathrm{kg} \mathrm{m}^{2}\right)\end{array} \\
I_{S}\end{array}$} \\
\hline & & $D_{1}$ & $D_{2}$ & $K_{1}$ & $K_{2}$ & $C_{1}$ & $C_{2}$ & \\
\hline Value & 18000 & 1.95 & 1.05 & $2 \times 10^{6}$ & $5 \times 10^{6}$ & $10 \times 10^{3}$ & $20 \times 10^{3}$ & 55500 \\
\hline
\end{tabular}

It follows from Table 1 that the static axle loads of the vehicle are $P_{1}=61778 \mathrm{~N}$ and $P_{2}$ $=114730 \mathrm{~N}$ for axle 1 and 2 respectively. These values depend on the mass of the vehicle, $m_{s}$, and the location of its centre of gravity, $o$.

It is assumed that all of the vehicle properties are known. In reality, these properties would be unknown and the first step towards the implementation of the algorithm would require the calibration of the vehicle model, which can be a challenging task. The latter involves the determination of the model properties based on measurements of the vehicle response to an excitation source, i.e., a known road profile using combinatorial optimisation [37] [37] or a vibration test using modal analysis [38].

The half-car equations of motion for the sprung mass bounce and pitch motions, $y_{s}$ and $\theta_{s}$ respectively, are given by: 


$$
\begin{gathered}
m_{s} \ddot{y}_{s}+F_{t, 1}+F_{t, 2}=0 \\
I_{s} \ddot{\theta}_{s}+D_{1} F_{t, 1}-D_{2} F_{t, 2}=0
\end{gathered}
$$

The term $F_{t, i}$ represents the dynamic wheel contact force at wheel $i$ :

$$
F_{t, i}=K_{i}\left(y_{s}-(-1)^{i} D_{i} \theta_{s}-w_{v, i}\right)+C_{i}\left(\dot{y}_{s}-(-1)^{i} D_{i} \dot{\theta}_{s}-\dot{w}_{v, i}\right) ; i=1,2
$$

where $w_{v, i}$ is the total displacement under wheel $i$. This parameter can be defined in terms of the road profile displacement and bridge displacement under wheel $i: r_{i}$ and $w_{b, i}$ respectively:

$$
w_{v, i}=w_{b, i}+r_{i} ; \quad i=1,2
$$

The total wheel contact force is represented by $R_{i}$ :

$$
R_{i}=P_{i}-F_{t, i} ; i=1,2
$$

where $P_{i}$ is the static load of the vehicle at axle $i$. The forces $R_{i}$ are the total vertical forces applied by the vehicle to the bridge structure.

\section{$2.2 \quad$ Bridge model}

The bridge is represented by a simply supported FE beam model (Fig. 2) of total span length $L$. It consists of discretised beam elements with 4 degrees of freedom which have constant mass per unit length, $\mu$, modulus of elasticity $E$ and second moment of area $J$. 


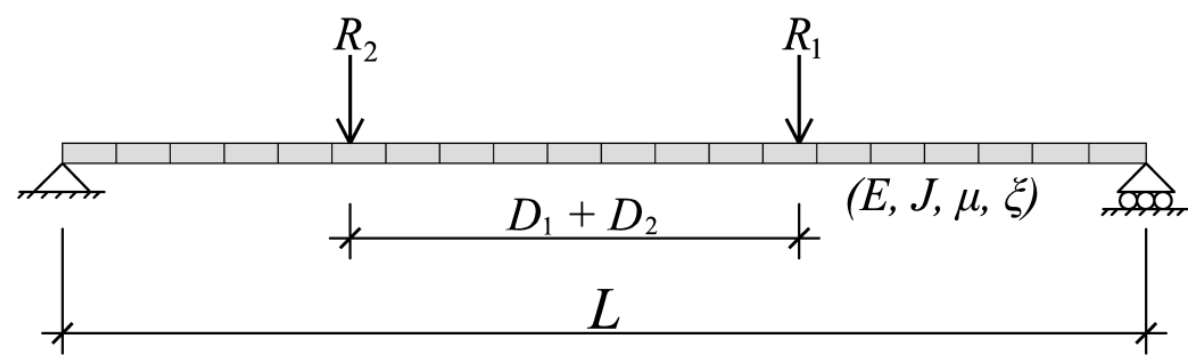

Fig. 2 Finite element beam model

The response of a discretised beam model to a series of moving time-varying forces is given by the system of equations:

$$
\mathbf{M}_{\mathbf{b}} \ddot{\mathbf{w}}_{\mathbf{b}}+\mathbf{C}_{\mathbf{b}} \dot{\mathbf{w}}_{\mathbf{b}}+\mathbf{K}_{\mathbf{b}} \mathbf{w}_{\mathbf{b}}=\mathbf{f}_{\mathbf{b}}
$$

where $\mathbf{M}_{\mathbf{b}}, \mathbf{C}_{\mathbf{b}}$ and $\mathbf{K}_{\mathbf{b}}$ are global mass, damping and stiffness matrices of the beam model respectively, $\mathbf{w}_{\mathbf{b}}, \dot{\mathbf{w}}_{\mathbf{b}}$ and $\ddot{\mathbf{w}}_{\mathbf{b}}$ are the global vectors of nodal bridge displacements and rotations, their velocities and accelerations respectively, and $\mathbf{f}_{\mathbf{b}}$ is the global vector of forces applied to the bridge nodes. The set of forces acting on the bridge nodes $\mathbf{f}_{\mathbf{b}}$ is obtained from $R_{i}$ (Eq. (5)) through a location matrix that distributes the force applied to a beam element to equivalent forces acting on the nodes.

The properties of the three bridge spans used in this investigation are given in Table 2.

Table 2 Finite element beam properties

\begin{tabular}{ccccc}
\hline $\begin{array}{c}\text { Span } \\
\text { Length, } \\
L(\mathrm{~m})\end{array}$ & $\begin{array}{c}\text { Modulus of } \\
\text { elasticity, } E \\
\left(\mathrm{~N} \mathrm{~m}^{-2}\right)\end{array}$ & $\begin{array}{c}\text { Second } \\
\text { moment of } \\
\text { area, } J\left(\mathrm{~m}^{4}\right)\end{array}$ & $\begin{array}{c}\text { Mass per } \\
\text { unit length, } \\
\mu\left(\mathrm{kg} \mathrm{m}^{-1}\right)\end{array}$ & $\begin{array}{c}\text { 1st natural } \\
\text { frequency of } \\
\text { vibration, } f_{b, 1}(\mathrm{~Hz})\end{array}$ \\
\hline 15 & $3.5 \times 10^{10}$ & 0.5273 & 28125 & 5.66 \\
\hline 25 & $3.5 \times 10^{10}$ & 1.3901 & 18358 & 4.09 \\
\hline 35 & $3.5 \times 10^{10}$ & 3.4162 & 21752 & 3.01 \\
\hline
\end{tabular}


The damping ratio of the bridge, $\xi$, is varied; this is discussed in more detail in Sections 3 and 4. Although complex damping mechanisms may be present in the structure, viscous damping is typically used for bridge structures and deemed to be sufficient to reproduce the bridge response accurately. Therefore, Rayleigh damping is adopted here to model viscous damping and it is given by:

$$
\mathbf{C}_{\mathbf{b}}=\alpha \mathbf{M}_{\mathbf{b}}+\beta \mathbf{K}_{\mathbf{b}}
$$

where $\alpha$ and $\beta$ are constants. The damping $\xi$ is assumed to be the same for all modes and $\alpha$ and $\beta$ are obtained from $\alpha=2 \xi \omega_{1} \omega_{2} /\left(\omega_{1}+\omega_{2}\right)$ and $\beta=2 \xi /\left(\omega_{1}+\omega_{2}\right)$ where $\omega_{1}$ and $\omega_{2}$ are the first two natural frequencies of the bridge [39].

\subsection{Interaction procedure}

The dynamic interaction between the vehicle and the bridge is implemented in Matlab using an iterative procedure described by Cantero et al [40]. The equations of motion for the vehicle travelling over a road profile (ignoring the bridge) are solved using the Wilson-Theta integration scheme [41, 42]. The vertical forces of the vehicle calculated from Eq. (5) are applied to the bridge model. The differential equations of the beam (Eq. (6)) are then solved, also using the Wilson-Theta integration scheme. The vertical displacements of the bridge due to the vehicle forces are calculated and added to the road profile heights to form an updated 'profile'. The vertical forces applied by the wheels are re-calculated for the vehicle crossing the new updated profile and applied to the bridge model again to obtain updated bridge displacements. This process is repeated until convergence is obtained. The convergence

criterion adopted in this paper is that the percentage difference in displacement under a 
wheel, $w_{b, i}$, between two consecutive iterations becomes less than or equal to $0.01 \%$. The optimal value of the parameter $\theta=1.420815$ is used for unconditional stability in the integration schemes [43].

In the simulations, it is assumed that there are two measurement sources; accelerations at each axle (Fig. 1), that are obtained as input for the algorithm. These accelerations are described using the following equation:

$$
\ddot{y}_{s, i}=\ddot{y}_{s}-(-1)^{i} D_{i} \ddot{\theta}_{s} ; i=1,2
$$

\section{Damping identification methodology}

The novel method presented in this paper for the identification of damping involves a sequential procedure. For the VBI model investigated here, the average computational time is only 1.5 minutes and this process can be broken down into six distinct steps that are summarised in Fig. 3. In the first step, the damping ratio of the bridge is set equal to arbitrary specific value, e.g., $3 \%$. This is the target damping ratio to be identified by the process. The 'measured' vehicle accelerations, $\ddot{y}_{s, i}$, are generated in Matlab using the VBI model outlined

in Section 1. These accelerations are then converted to sprung mass bounce $\ddot{\theta}_{s}$ and pitch accelerations $\ddot{y}_{s}$ using Eq. (8) to be substituted into Eqs. (1) and (2).

In the second step, the total wheel contact forces $\left(R_{i}\right)$ are calculated. By solving Eqs. (1) and (2) simultaneously, the dynamic forces $F_{t, i}$ can be obtained for each instant in time. The total wheel contact forces can then be obtained from Eq. (5). The total displacements under each wheel $\left(w_{v, i}\right)$ are calculated in the third step by solving Eq. (3) as a $1^{\text {st }}$ order differential 
equation in $w_{v, i}$. This equation is solved using the Runge-Kutta method. The sprung mass bounce and pitch velocities $\left(\dot{y}_{s}, \dot{\theta}_{s}\right)$ and displacements $\left(y_{s}, \theta_{s}\right)$ are obtained by integration of the measured accelerations from the first step. A linear correction is then applied to $w_{v, i}$ which ensures that it is not affected significantly by any drift error arising from the integration.

In the fourth step, the contact forces $R_{i}$ obtained in step 2 are applied to the FE beam model described in Section 2.2. An initial estimate of the damping ratio $\xi_{\text {est }}$ is given to the beam based on typical values, to obtain the displacements due to the moving loads (Eq. (6)). Then, the displacement response of the beam, $w_{b, i}$, under each force is calculated. This process is repeated for a range of damping estimates ranging from $0.5 \%$ up to $6 \%$ in steps of $0.1 \%$, giving a total of 56 estimates. The fifth step involves rearranging and evaluating Eq. (4) to obtain estimates of the values of $r_{i}$ for each damping estimate by subtracting each range of $w_{b, i}$ (step 4) from the solution of $w_{v, i}$ obtained in step 3.

$$
r_{e s t, i}=w_{v, i}-w_{b, i} \quad i=1,2
$$

The resulting values of $r_{e s t, i}$ are effectively road profile height estimates under each wheel; there are 56 road profile estimates under each wheel corresponding to the 56 damping estimates. In the sixth and final step, the bridge damping ratio is found. As the wheels follow each other along the same wheel path, the profile estimates under each wheel ( $r_{e s t, 1}$ and $\left.r_{e s t, 2}\right)$ should be equal for the correct damping ratio. To identify the optimal value for damping from the range of 56 estimates investigated, a least squares error minimisation process is used, summing over all measurements in time, $t$, to obtain the error function $\mathrm{r}_{\text {error }}$ (Eq. (10)). This process results in 56 values of the least squares error function $\mathrm{r}_{\text {error }}$, 
corresponding to the 56 road profile estimates under each wheel. The optimal damping ratio is identified as that which corresponds to the minimum least squares error between profile estimates under each wheel, i.e., the minimum value of the error function $r_{\text {error }}$ in Eq. (10).

$$
r_{\text {error }}=\sum_{t}\left(r_{e s t, 1}-r_{e s t, 2}\right)^{2}
$$

1. Generate 'measured' axle accelerations $\ddot{y}_{s, i}$ using VBI model

- Convert $\ddot{y}_{s, i}$ to $\ddot{y}_{s}$ and $\ddot{\theta}_{s}$ using Eq. (8)

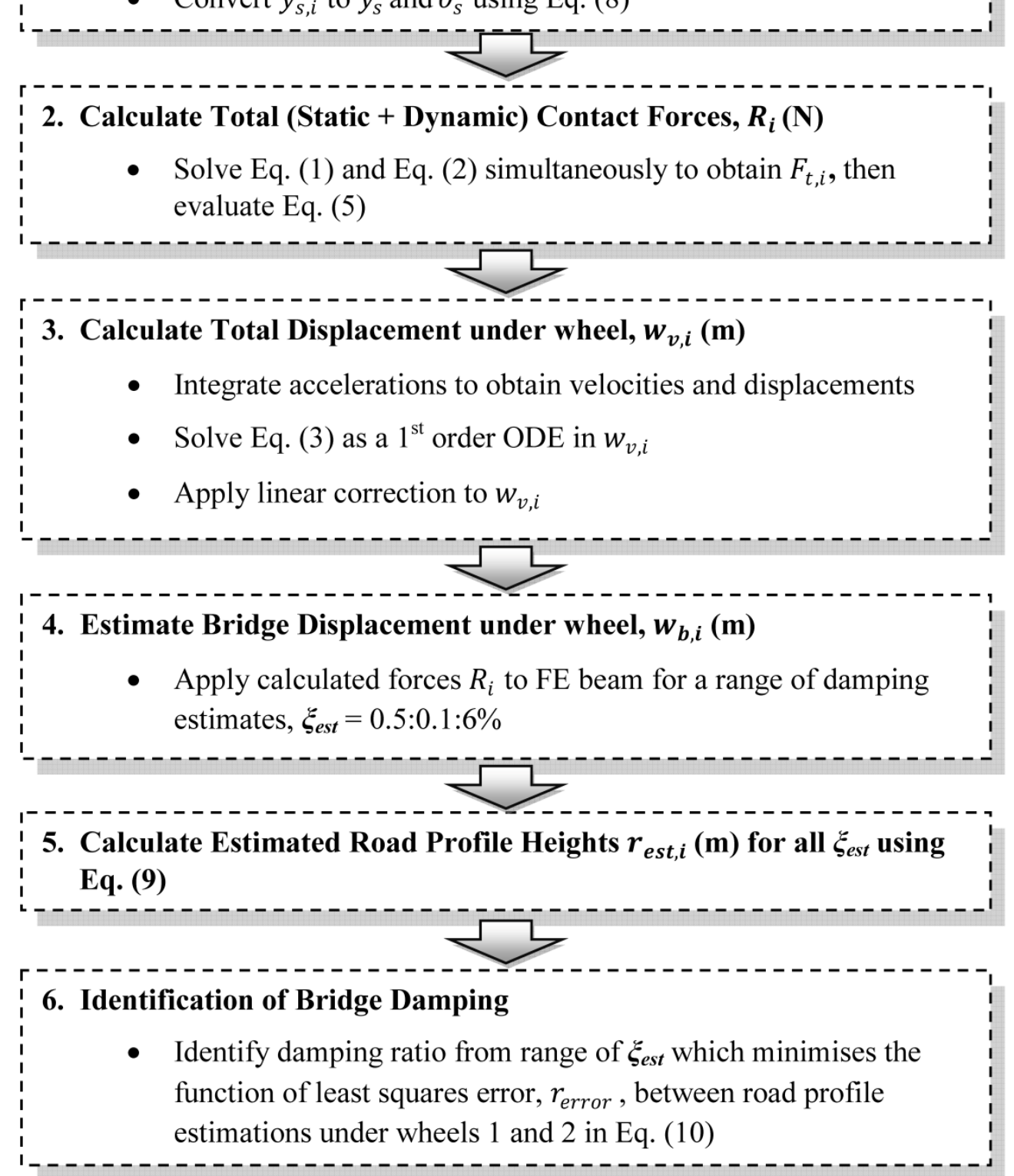

Fig. 3 Damping identification algorithm 


\section{Results and discussion}

In this section, the damping identification method outlined in Section 3 is tested via theoretical simulations using the VBI model described in Section 1. The properties varied in the simulations are the bridge span, vehicle velocity and the damping ratio of the bridge. A road profile is included in simulations and the irregularities of this profile are randomly generated according to the ISO standard [44] for a road class 'A' (very good profile, as expected in a well maintained highway) unless otherwise stated.

\subsection{Generation of vehicle axle accelerations}

The method proposed in this paper requires only the measurement of a vehicle's axle accelerations to identify the damping ratio of the bridge. For the purposes of this theoretical investigation, 'measured' axle accelerations are simulated artificially at a scanning frequency of $8192 \mathrm{~Hz}$ for bridge spans of 15, 25 and 35 metres and vehicle velocities from $10 \mathrm{~m} \mathrm{~s}^{-1}$ to $30 \mathrm{~m} \mathrm{~s}^{-1}$. The damping ratio of the bridge is varied between $1 \%$ and $5 \%$ in steps of $0.5 \%$, these values representing the damping which the proposed method aims to identify. An example of the simulated axle accelerations generated by the VBI model for a damping ratio of $3 \%$ is shown in Fig. 4. 


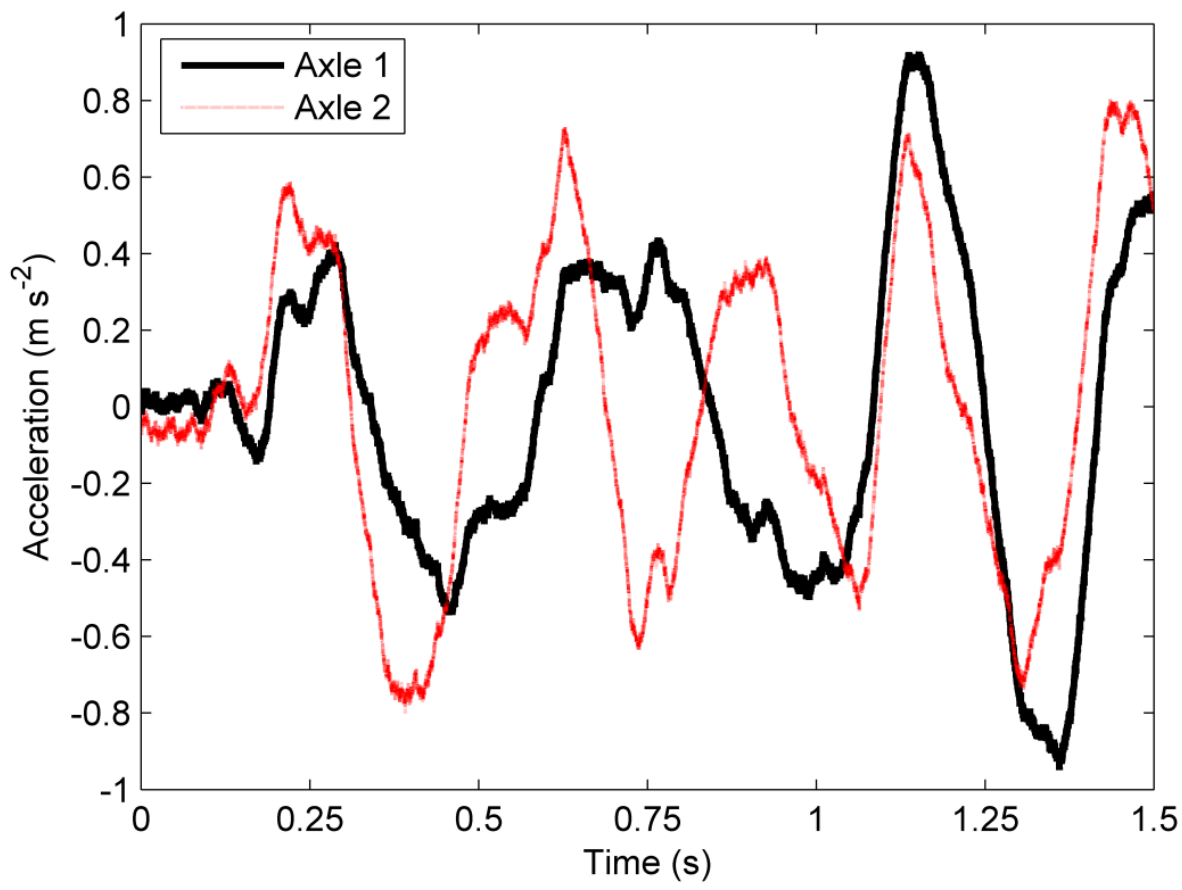

Fig. 4 'Measured' axle accelerations for vehicle travelling at $10 \mathrm{~m} \mathrm{~s}^{-1}$ across a $15 \mathrm{~m}$ bridge with $3 \%$ damping.

\subsection{Total contact forces}

The total contact forces, $R_{i}$, are calculated from the equations of motion of the vehicle in the second step of the algorithm (Eqs. (1), (2) and (5)). Fig. 5 shows an example of the calculated forces for the vehicle travelling across a $15 \mathrm{~m}$ bridge span at $10 \mathrm{~m} \mathrm{~s}^{-1}$. Again, the bridge's damping ratio is $3 \%$. 

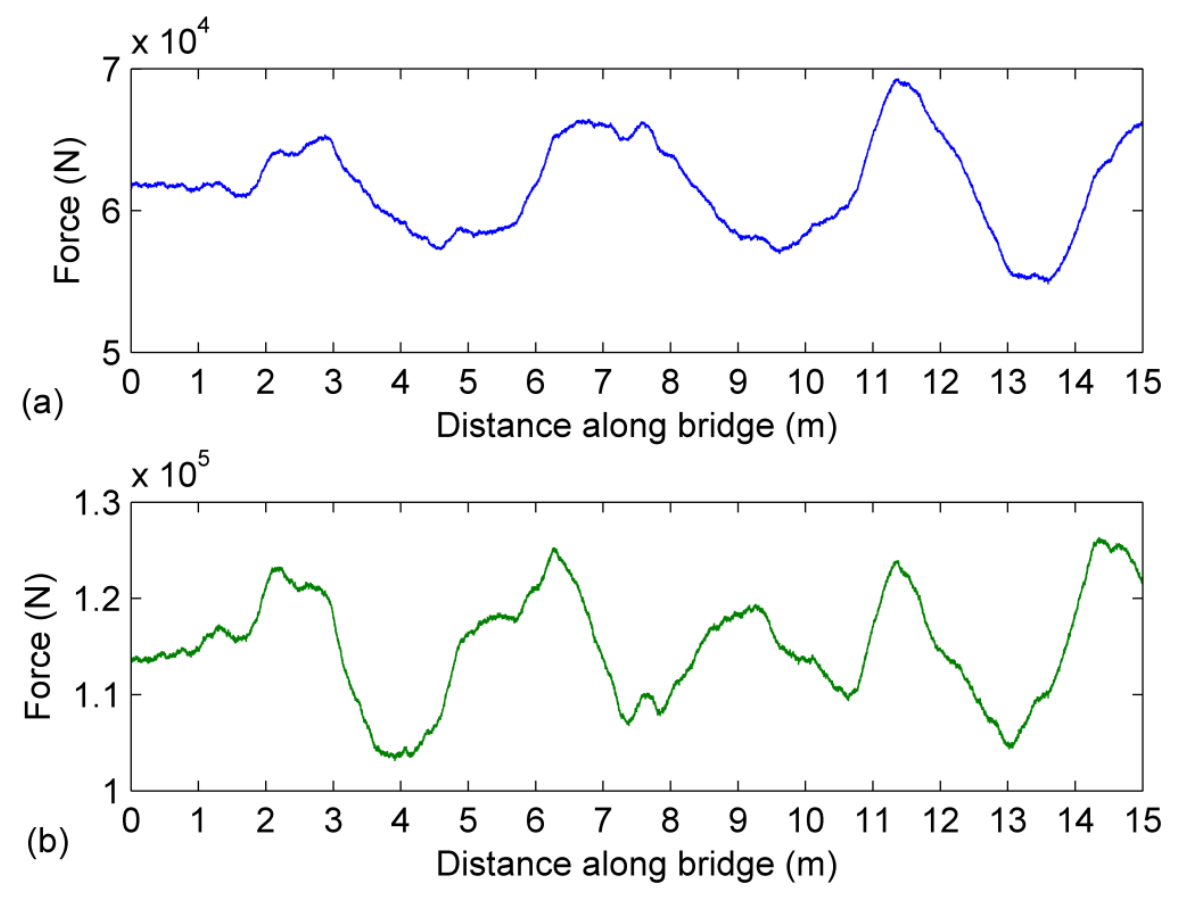

Fig. 5 Calculated total wheel contact forces, $R_{i}$, for the vehicle travelling at $10 \mathrm{~m} \mathrm{~s}^{-1}$ across a $15 \mathrm{~m}$ bridge with $3 \%$ damping; (a) $1^{\text {st }}$ axle, (b) $2^{\text {nd }}$ axle.

\subsection{Total displacement under the wheel}

Fig. 6 illustrates an example of the total displacements under each wheel of the vehicle which are calculated in the third step of the algorithm (Eq. (3)). The displacements shown are calculated for the same vehicle crossing the same $15 \mathrm{~m}$ bridge with $3 \%$ damping at $10 \mathrm{~m} \mathrm{~s}^{-1}$. As the contact point of each wheel experiences the same road profile, the only differences are due to differences in bridge displacement. Given the axle spacing of $3 \mathrm{~m}$, the $2^{\text {nd }}$ axle reaches a given point 0.3 seconds after the $1^{\text {st }}$ at which time the vehicle has moved and the bridge has undergone a change in displacement. The method calculates the high and low frequency components of these displacements very accurately. The average error of the calculated displacements in Fig. 6 is $1.5 \times 10^{-6} \mathrm{~m}$, which corresponds approximately to an average percentage error of $0.1 \%$. This level of accuracy is consistent for almost all properties investigated although a low frequency drift error is evident at particular velocities and spans. 
The latter is attributed to the double integration of accelerations by the Runge - Kutta method used to solve for the displacements. However, it is observed that this error does not significantly affect the accuracy of the damping identification.

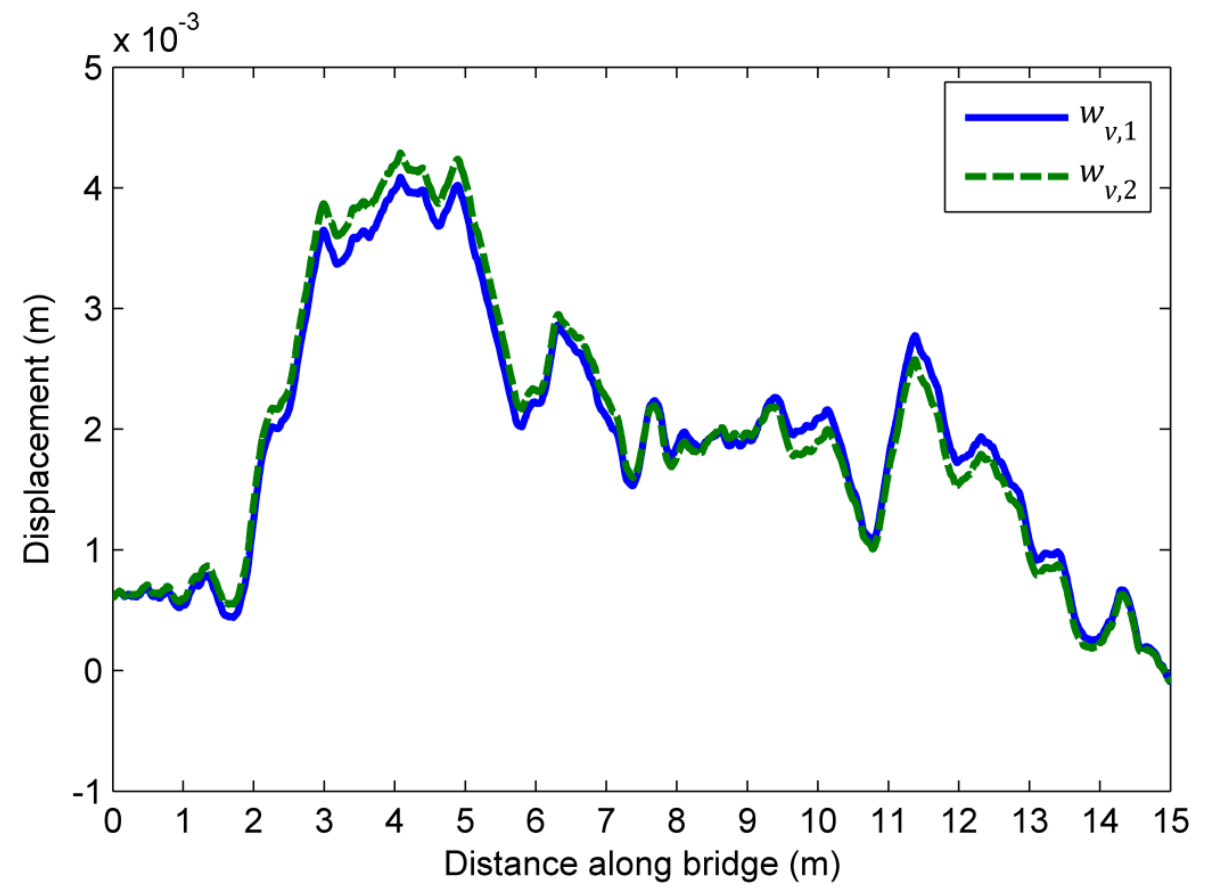

Fig. 6 Calculated total wheel displacements, $w_{v, i}$, for a $15 \mathrm{~m}$ bridge.

\subsection{Estimated bridge displacements}

Once the contact forces $R_{i}$ have been calculated using the 'measured' accelerations, it is possible to calculate bridge displacements under each wheel for a range of damping ratios using Eq. (6). Fig. 7 shows the bridge displacements calculated under each wheel due to the contact forces shown in Fig. 5 when assuming a 3\% damping ratio. Since the true damping used in the simulations is $3 \%$, the displacements in this figure are expected to be the most accurate estimates obtained from the range of damping ratios considered. It is important to note the magnitude of the bridge displacement in Fig. 7 compared to that of the total 
displacements in Fig. 6 - the contribution of the bridge response to the total displacement is small in comparison to the road profile component. In past studies $[12,15,27]$, this difference in magnitude was credited as being one of the sources of difficulty in detecting bridge dynamic parameters from the vehicle response in the presence of a rough road surface profile. However, the algorithm presented in this paper minimizes the impact of this problem. Instead of the road profile just adding an extra input excitation to the VBI model, the algorithm identifies the correct value for the damping ratio of the bridge by considering the differences in displacement under the two wheels which effectively removes the influence of road profile.

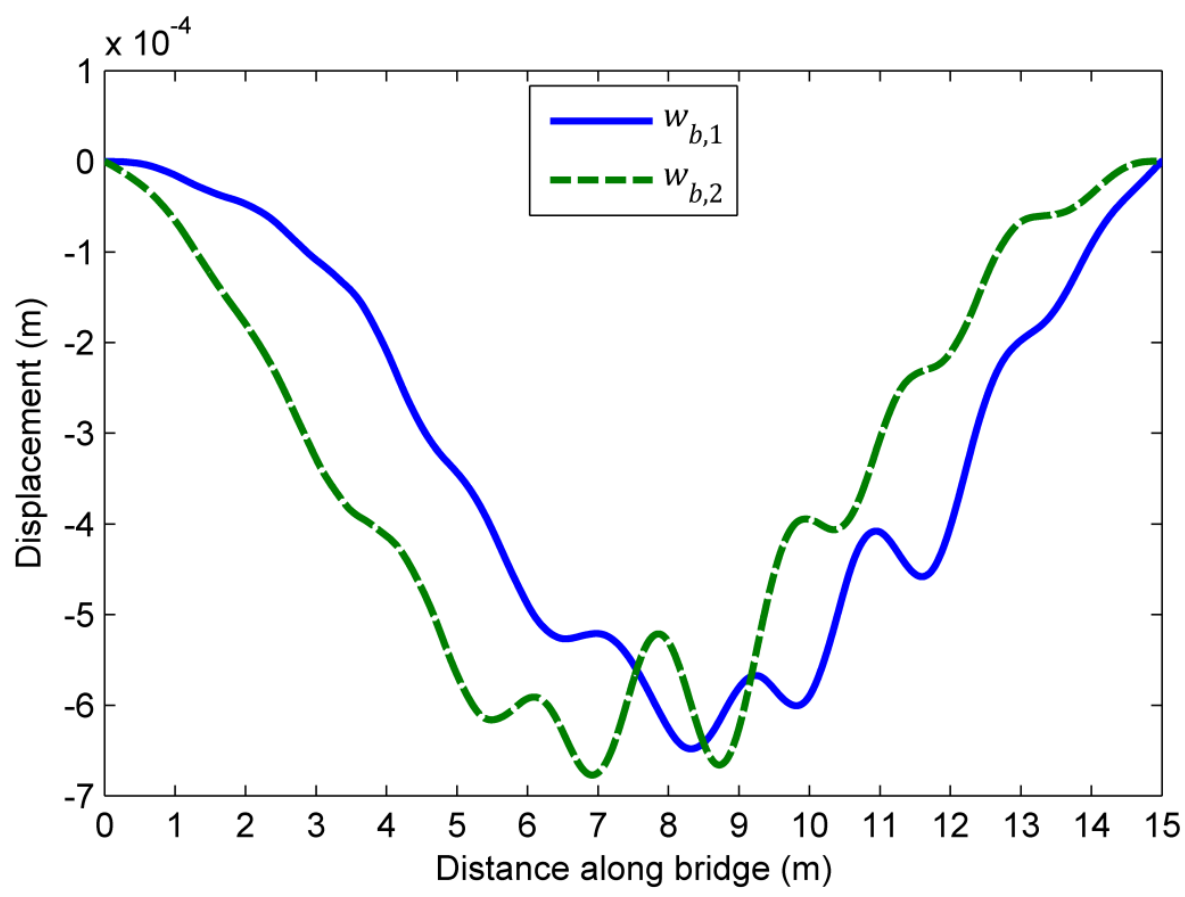

Fig. $7 \quad$ Estimated bridge displacements, $w_{b, i}$, under each wheel for a $15 \mathrm{~m}$ bridge.

Vehicle velocity is $10 \mathrm{~m} \mathrm{~s}^{-1}$. Damping ratio estimate is $3 \%$. 


\subsection{Estimated road profile heights}

From step 4 of the identification algorithm, a series of estimated bridge displacements under each wheel exist, i.e., one pair of bridge displacements for every damping ratio estimate $\left(\xi_{\text {est }}\right)$ used in simulations. As discussed in Section 3, a series of estimated road profile heights, $r_{e s t, i}$, are obtained in step 5 of the algorithm by subtracting the series of estimated bridge displacements, $w_{b, i}$, from the calculated total displacements, $w_{v, i}$ (Eq. (9)). Fig. 8 shows the full series of estimated road profile heights under each wheel for the vehicle crossing the 15 $\mathrm{m}$ bridge at $10 \mathrm{~m} \mathrm{~s}^{-1}$. These correspond to damping ratio estimates ranging from $0.5 \%$ to $6 \%$ in steps of $0.1 \%$. This means that there are 56 estimated road profiles plotted in both Fig. 8(a) and Fig. 8(b), although they are so similar that they are indistinguishable at the scale of the figure.

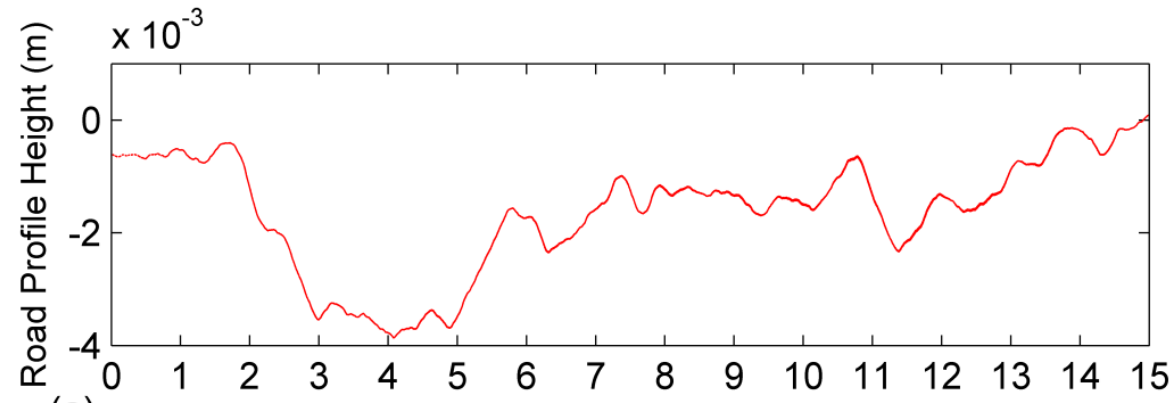

(a)

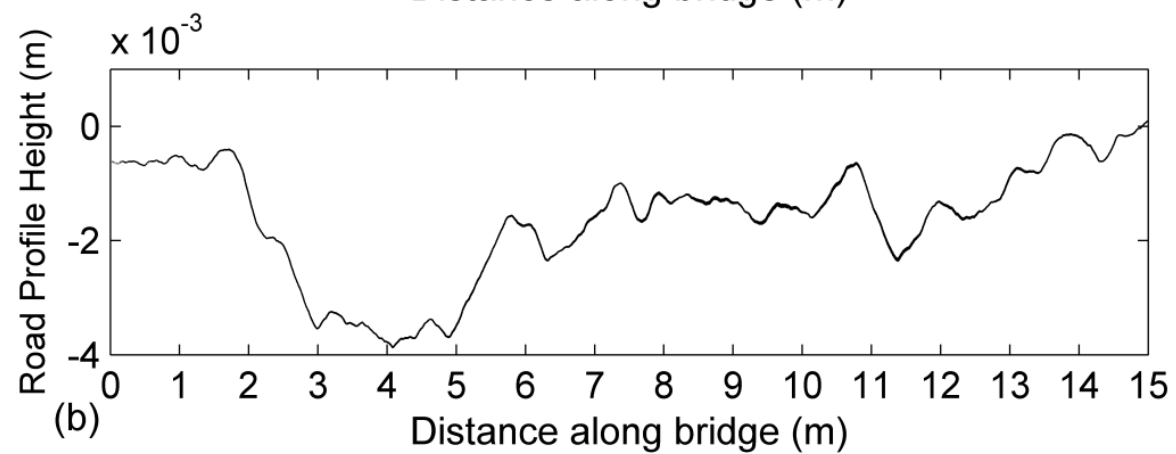

Fig. 8 Estimated road profile heights, $r_{e s t, i}$, under (a) first wheel (b) second wheel for vehicle crossing $15 \mathrm{~m}$ bridge at $10 \mathrm{~m} \mathrm{~s}^{-1}$. Damping range is from $0.5 \%$ to $6 \%$ in steps of $0.1 \%$. 
From Fig. 8 it can be seen that the variation in the estimated road profile heights with damping is very small. This relates to the point raised in Section 4.4 regarding the bridge contribution to the total displacement under the wheel. The variation in the damping estimate affects the bridge displacement response directly. As the bridge contribution to $w_{v, i}$ is small compared to that of the road profile component, it follows that the contribution of the variation of the bridge response with damping is small in the resulting road profile estimates. However, this does not affect the accuracy of the algorithm as it is the difference between the estimates of road profile under each wheel that is important for the identification of the correct value for damping. The least squares error between the profile heights under the first and second wheels (Eq.(10)) is plotted against damping in Fig. 9 and shows that the minimum, as expected, corresponds to the true damping of $3 \%$.

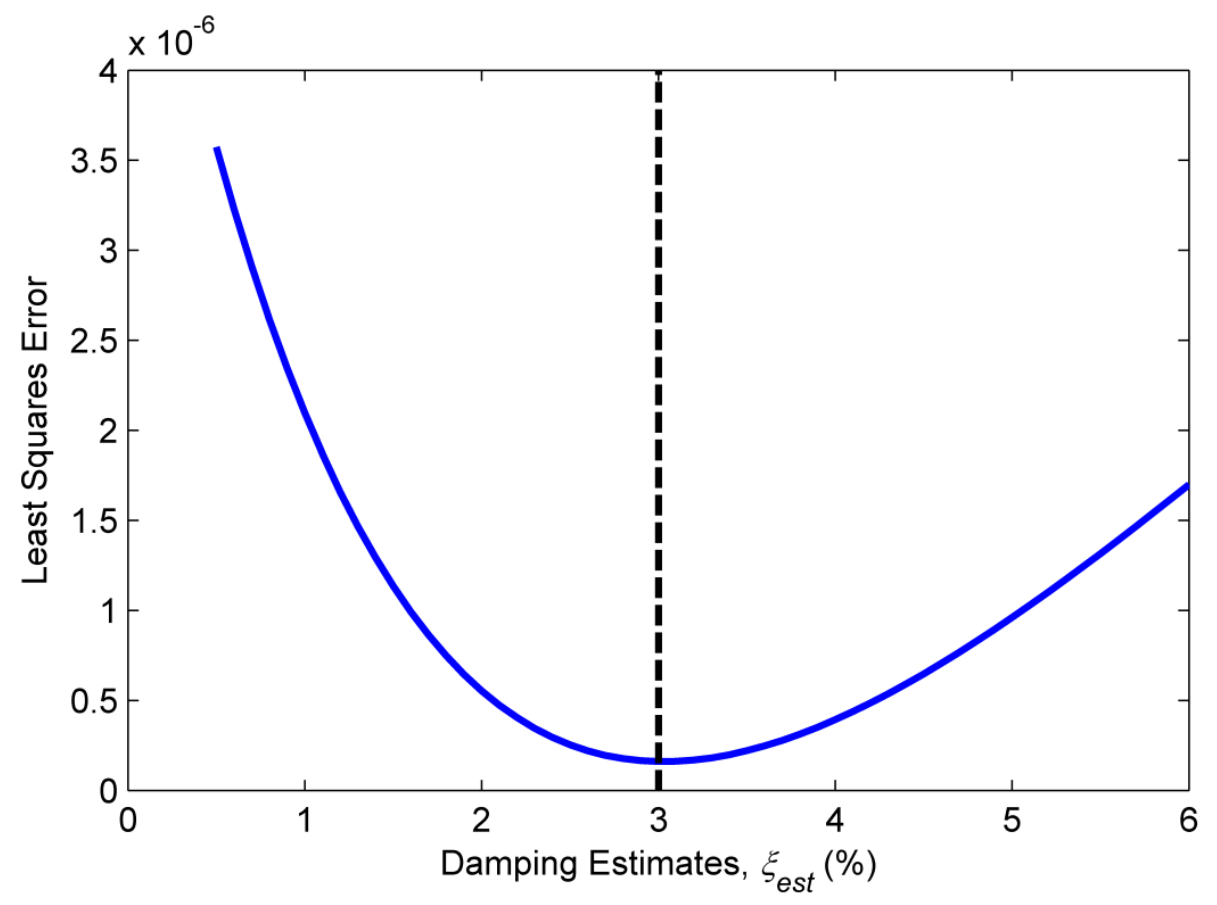

Fig. 9 Least squares error, $r_{\text {error }},(-)$ versus damping estimates $\left(\xi_{\text {est }}\right)$. Target damping ratio is $3 \%(\boldsymbol{- n} \boldsymbol{-})$. 


\subsection{Bridge damping estimates}

Fig. 10 shows the final output of the algorithm - the optimal values of the estimated damping ratios - identified for all bridge spans and velocities investigated. The target value of damping for the results shown is $3 \%$. Overall, the damping estimates are very accurate. For the $15 \mathrm{~m}$ span the average absolute percentage estimation error is $8 \%$ and the standard deviation of this error is $6.5 \%$. The results shown for the $25 \mathrm{~m}$ span have an average absolute percentage estimation error of $1.7 \%$ and the standard deviation of this error is $3.2 \%$. Finally, the average absolute percentage estimation error obtained for the $35 \mathrm{~m}$ span is $2 \%$ with a standard deviation of $1.4 \%$. Similar results are obtained for other target values of damping: $1 \%$ to $5 \%$ in steps of $0.5 \%$. The algorithm is generally less accurate for shorter bridge spans.

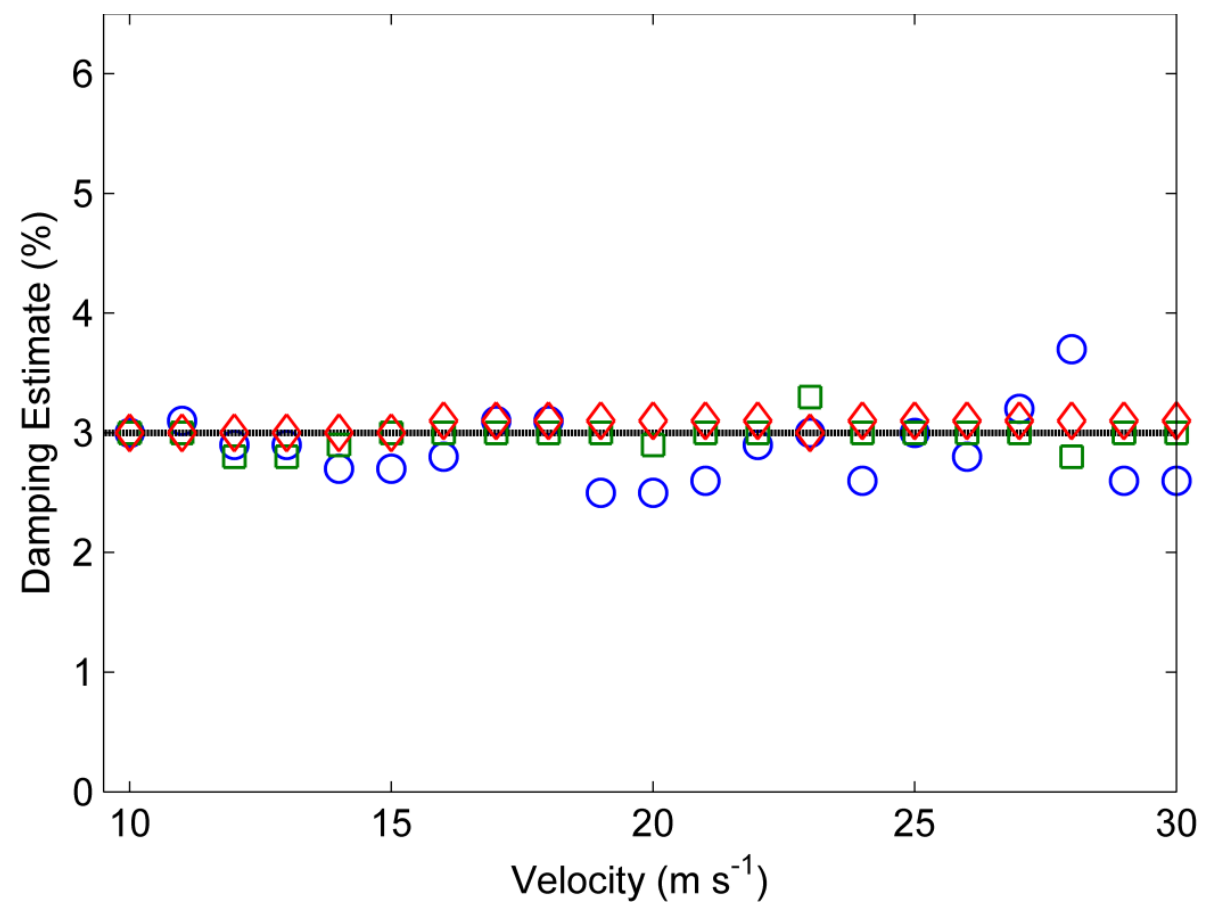

Fig. 10 Optimal bridge damping estimates for bridge spans of $15 \mathrm{~m}(\mathrm{O}) 25 \mathrm{~m}(\square)$ and $35 \mathrm{~m}(\diamond)$. Target damping ratio is $3 \%(---)$. ISO Class 'A' road profile. 
Until this point, results have only been shown for a target value of $3 \%$ damping. Fig. 11 summarises the results for the other damping levels through histograms for each bridge span. The histograms show the frequency of the occurrence of particular percentage errors in damping identification. The total number of simulations represented in Fig. 11 is 567; this number consists of the combination of 21 velocities $\left(10 \mathrm{~m} \mathrm{~s}^{-1}\right.$ to $\left.30 \mathrm{~m} \mathrm{~s}^{-1}\right)$ and 9 target damping values ( $1 \%$ to $5 \%$ in steps of $0.5 \%)$ for each of the three bridge spans. Overall, the results are quite positive. $88 \%$ of the total number of simulations are less than $10 \%$ inaccurate in damping estimation. For the $25 \mathrm{~m}$ span (Fig. 11(b)) $96 \%$ of the errors in damping identification are less than 10\%. The $35 \mathrm{~m}$ span (Fig. 11(c)) provides the most accurate results with $100 \%$ of errors in damping identification less than $10 \%$. The wide spread of percentage errors in Fig. 11(a) provides evidence of the reduced accuracy of the algorithm for shorter spans. The reason for this is that the shorter span is stiffer and as a result it does not produce a sufficiently large dynamic response under the forced excitation by the vehicle. However, 68\% of the estimate errors in Fig. 11 (a) are still less than 10\%. In total in Fig. 11, $0.88 \%$ of the bridge/velocity combinations, i.e., 5 out of the 567 simulations provide damping estimation error greater than $30 \%$. It is recommended in practice to cross the vehicle over the bridge at more than one velocity to ensure consistency between estimates and eliminate error. 

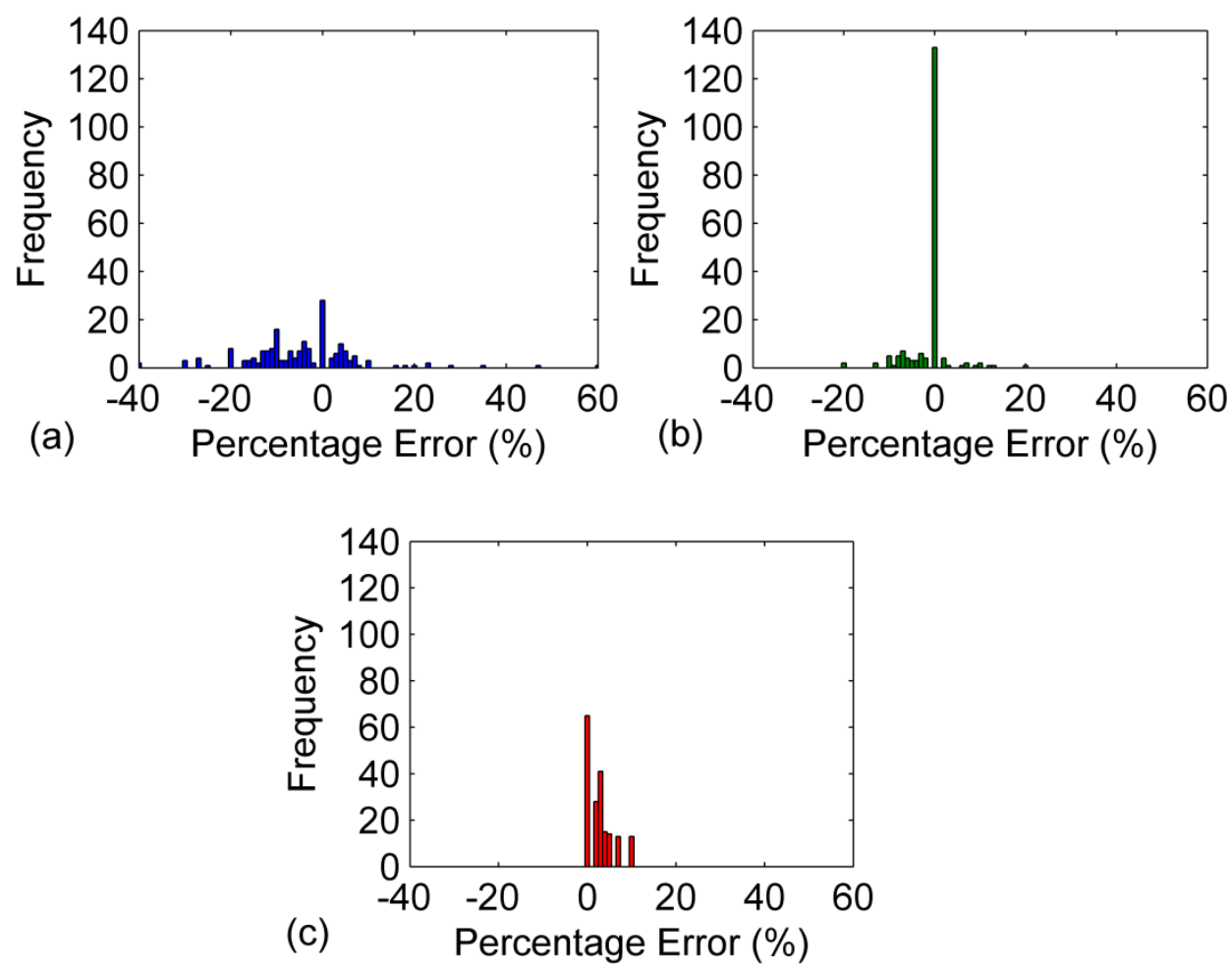

Fig. 11 Histograms of damping estimate percentage error for bridge spans of (a) $15 \mathrm{~m}$ (b) $25 \mathrm{~m}$ and (c) $35 \mathrm{~m}$.

\subsubsection{Sensitivity to road roughness}

As past studies encountered difficulties in detecting bridge dynamic parameters from the vehicle response in the presence of a rough surface profile, this section tests the sensitivity of the algorithm to the road profile roughness. Results presented thus far were for an ISO class 'A' road profile. Here, an ISO class ' $C$ ' (average) road profile is randomly generated according to the ISO standard [44] and included in the simulations. The road irregularities are higher than for a road class 'A', but they induce larger vehicle dynamic forces and bridge displacements. The results of the damping identification algorithm for this road profile are shown in Fig. 12. The target damping ratio is 3\%. A comparison of Figs. 10 and 12 shows that the accuracy of the algorithm is not significantly affected by road profile roughness which is a big advantage of the approach. Also, the average absolute percentage errors of 
damping estimates shown in Fig. 12 are 13\%, $0.7 \%$ and $2.1 \%$ corresponding to the bridge spans of $15 \mathrm{~m}, 25 \mathrm{~m}$ and $35 \mathrm{~m}$ respectively. As before, the least accurate results are obtained for the shortest span due to its stiffness and the small differences in deflected shapes when damping changes. The average error for the $15 \mathrm{~m}$ span has increased compared to the corresponding average error for the very good road profile but the accuracy for the $25 \mathrm{~m}$ and $35 \mathrm{~m}$ spans has not been affected significantly by the increase in road roughness. Compared to results for the very good road profile, the standard deviation for the $15 \mathrm{~m}$ span has increased from $6.5 \%$ in Fig. 10 to $13 \%$ in Fig. 12. The standard deviation of the errors for the $25 \mathrm{~m}$ and $35 \mathrm{~m}$ bridge spans are $1.3 \%$ and $1.4 \%$ respectively.

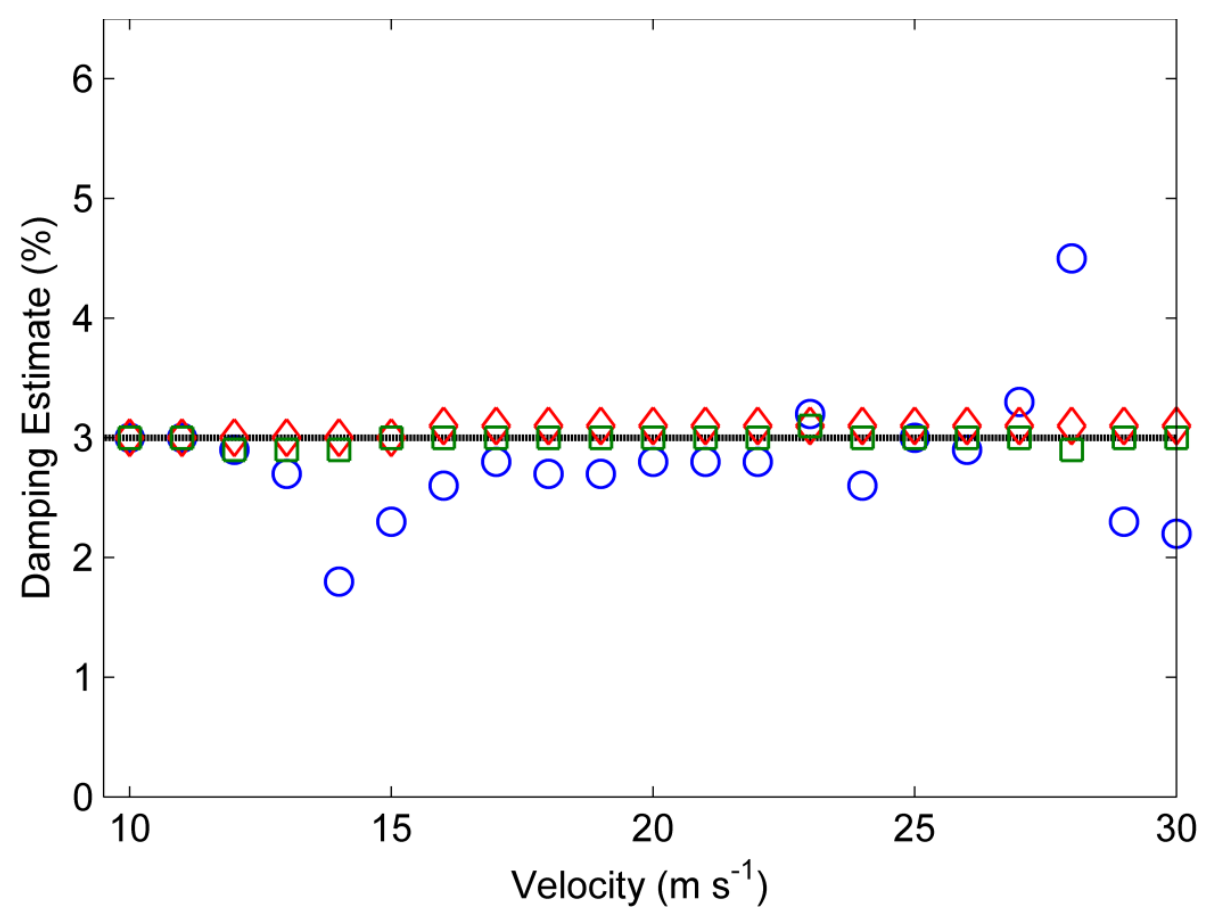

Fig. 12 Optimal bridge damping estimates for bridge spans of $15 \mathrm{~m}(\mathrm{O}) 25 \mathrm{~m}(\square)$ and $35 \mathrm{~m}(\diamond)$. Target damping ratio is $3 \%(---)$. ISO Class ' $\mathrm{C}$ ' road profile. 


\subsubsection{Sensitivity to random noise}

In practice, it is expected that the accuracy of the algorithm will be lower than in theoretical simulations due to errors such as those associated with modelling approximations (e.g., incorrect values of model parameters) and random noise. The latter is investigated by corrupting the measured acceleration signals from step 1 of the algorithm with an additive noise model based on a signal-to-noise ratio (SNR) of 20 (i.e., relative error in the measurements of 5\%). Noise is randomly added to the true accelerations by sampling a normal distribution of zero mean and standard deviation equal to the standard deviation of the true acceleration data divided by 20 [37]. The results of the damping identification algorithm using the corrupted accelerations are shown in Fig. 13. An ISO class 'A' road profile is used in simulations and the target damping ratio is $3 \%$. Before application of the algorithm, a low pass filter (with cut-off frequency of $100 \mathrm{~Hz}$ ) is applied to the vehicle accelerations which were contaminated with noise. The accuracy of the algorithm is similar to that obtained for noise-free accelerations in Fig. 10, except for the $15 \mathrm{~m}$ bridge. The average percentage errors in damping estimation for the $25 \mathrm{~m}$ and $35 \mathrm{~m}$ spans are $3.8 \%$ and $2.3 \%$ respectively which compare very well to the accuracy of the noise-free results. The standard deviations of the error for the $25 \mathrm{~m}$ and $35 \mathrm{~m}$ bridge spans are $3.7 \%$ and $2.8 \%$ respectively. 


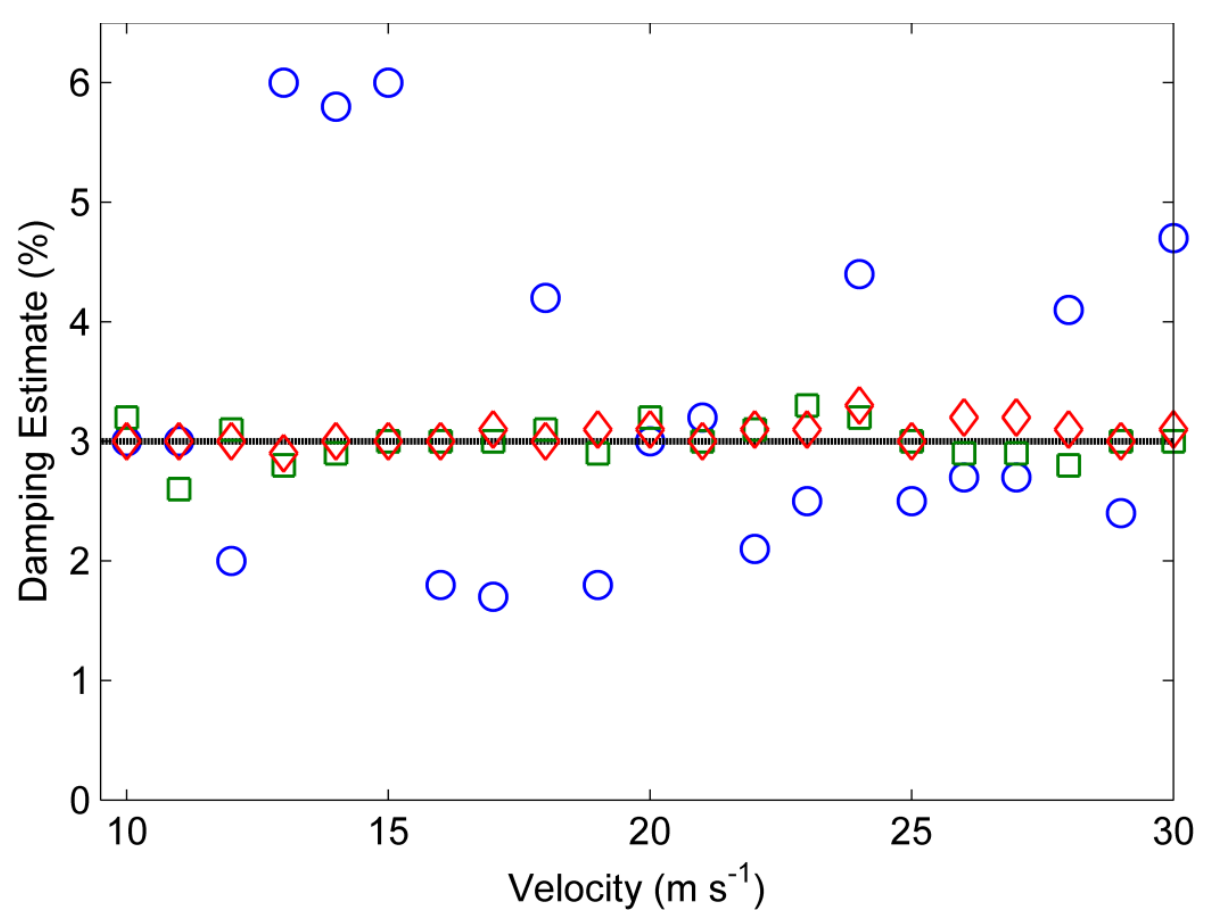

Fig. 13 Optimal bridge damping estimates obtained from noise corrupted accelerations with SNR $=20$ for bridge spans of $15 \mathrm{~m}(\bigcirc) 25 \mathrm{~m}(\square)$ and $35 \mathrm{~m}(\diamond)$. Target damping ratio is $3 \%(---)$. ISO Class 'A' road profile.

The accuracy of damping estimates for the $15 \mathrm{~m}$ bridge has decreased - considerably so between $13 \mathrm{~m} \mathrm{~s}^{-1}$ and $15 \mathrm{~m} \mathrm{~s}^{-1}$ - due to the corruption of the measured accelerations with noise. Overall, the addition of noise has increased the average absolute percentage error in damping estimation from $8 \%$ for the noise - free simulations to $35 \%$ for the $15 \mathrm{~m}$ bridge results in Fig. 13. The standard deviation of this error is $31 \%$. The low dynamic excitation of the bridge at some velocities is further hidden by the noise in the corrupted vehicle acceleration signal, which prevents a correct identification of damping. For longer bridge spans, the dynamic excitation of the bridge is larger and therefore is not as sensitive to noise. 


\subsubsection{Sensitivity to initial conditions}

The proposed algorithm requires a double integration of measured accelerations to obtain the velocities and displacements of the vehicle degrees of freedom. In practice, this can be a difficult procedure as knowledge of the Initial Conditions (ICs) of the velocity and displacement signals is necessary [45]. The investigation thus far assumed knowledge of the true ICs. To account for a scenario in which the ICs are unknown, the algorithm is implemented with an assumed IC. An assumed IC for body bounce displacement of $2 \times 10^{-3}$ $\mathrm{m}$ is adopted here while null initial conditions are assumed for the remaining ICs of body pitch velocity and displacement and the body bounce velocity.

The true IC of the vehicle can be obtained directly from the VBI model. They will vary between simulations as they are a function of the velocity of the vehicle and the road profile. It should be noted that the estimated body bounce displacement IC has been selected to be ten times the average true IC of the same degree of freedom. The results are shown in Fig. 14. The estimates are almost identical to those observed in Fig. 10 using true ICs. This can be illustrated by the average absolute percentage errors of the damping estimates shown in Fig. $14 ; 8 \%, 1.7 \%, 2 \%$ corresponding to the $15 \mathrm{~m}, 25 \mathrm{~m}$ and $35 \mathrm{~m}$ spans respectively. Also, the standard deviations of these errors are identical to the results obtained using the true ICs. Therefore, it is found that the algorithm is insensitive to the ICs chosen here. This is due to the mathematical basis of the algorithm which employs the difference between the estimated road profiles under each wheel to estimate damping. This difference is not affected by choosing incorrect ICs as long as a linear correction is applied to the calculated displacements under the wheels in step 3 of the algorithm. This linear correction effectively renders the algorithm solution independent of the ICs. 


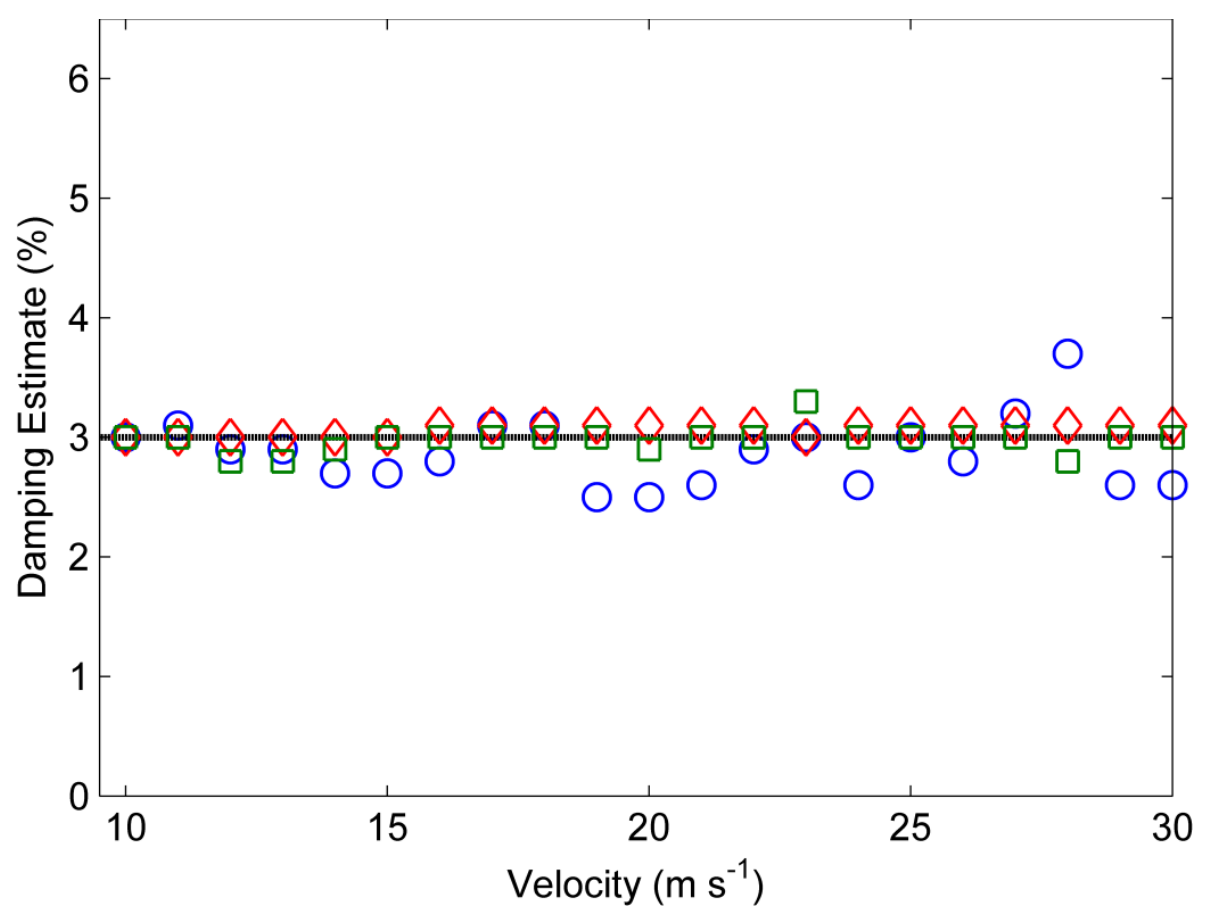

Fig. 14 Optimal bridge damping estimates obtained using incorrect initial vehicle conditions for bridge spans of $15 \mathrm{~m}(\mathrm{O}) 25 \mathrm{~m}(\square)$ and $35 \mathrm{~m}(\diamond)$. Target damping ratio is $3 \%(---)$. ISO Class ' $A$ ' road profile.

The correction is based on the true bridge displacement being zero at the entrance and the exit to the bridge, i.e., at $0 \mathrm{~m}$ and $15 \mathrm{~m}$ respectively in Fig. 6, therefore the only displacement each wheel experiences at these locations is the road profile height. This means that the (true) total displacements under each wheel should be equal when located over the supports. A linear correction technique is used to maintain this relationship. The correction is a linear function which varies with distance along the bridge and it is defined by its first and last values. The first value is the difference between the total calculated displacements under wheel $1, w_{v, 1}$, and wheel $2, w_{v, 2}$, at the entrance to the bridge. The last value is the corresponding difference between $w_{v, 1}$ and $w_{v, 2}$ at the exit of the bridge. Then, when applying the algorithm, $w_{v, 1}$ remains unaltered but $w_{v, 2}$ is corrected by subtracting the values corresponding to the linear variation suggested above. This ensures that the difference 
between displacements under the wheels is not affected significantly by any drift error arising from the integration.

\subsection{Modelling inaccuracies}

It has already been noted that in practice, the accuracy of the algorithm is expected to be lower than in theoretical simulations. It was shown in Section 4.6.2 that in general, the damping identification algorithm is not very sensitive to errors associated with low levels of signal noise. This section addresses errors which are associated with modelling approximations; specifically, the effects of using incorrect values of bridge and vehicle model parameters are investigated. Unless otherwise stated, results are presented in this section for simulations using an ISO class ' $A$ ' road profile, vehicle velocity of $20 \mathrm{~m} \mathrm{~s}^{-1}$ and the target damping ratio is $3 \%$.

\subsubsection{Bridge stiffness}

A reduction in bridge stiffness can occur due to the loss of cross-section or cracking [46] and with increased loading this reduction can worsen [47]. As a result, this property has been the focus of numerous damage assessment techniques [5]. Here, the uncertainty associated to the bridge stiffness is addressed by varying it along with damping when running the computer model. These simulations allow investigating the efficiency of the algorithm in predicting both stiffness and damping. Fig. 15(a) shows a 2D contour plot of the log of the least squares error (Eq. (10)) between road profile heights for varying damping ratio estimates and errors

in the stiffness of the $15 \mathrm{~m}$ bridge model. It can be seen that the minimum occurs for a damping ratio of $2.7 \%$ and stiffness error of $+0.5 \%$, i.e., the small error in stiffness does not 
have a significant effect on the damping estimate (matching the corresponding estimate in Fig. 10 where the exact value of bridge stiffness is employed). This figure suggests that an uncertainty in the bridge stiffness can be overcome by testing a range of stiffness values, whereby the values of stiffness and damping ratio providing a minimum least squares error $\left(r_{\text {error }}\right)$ are reasonable measures of their true values. Fig. 15(b) shows a 3D surface plot of the data in Fig. 15(a), including a wider range of percentage errors. This figure illustrates that an underestimation of the bridge stiffness provides larger least squares error than an overestimation of the same percentage. This can be explained by analysing Eqs. (9) and (10). An overestimation provides a stiffer bridge than reality, hence the bridge displacements under each wheel, $w_{b, i}(i=1,2)$, and consequently the differences between them, will be smaller having less of an influence on $r_{\text {error }}$.
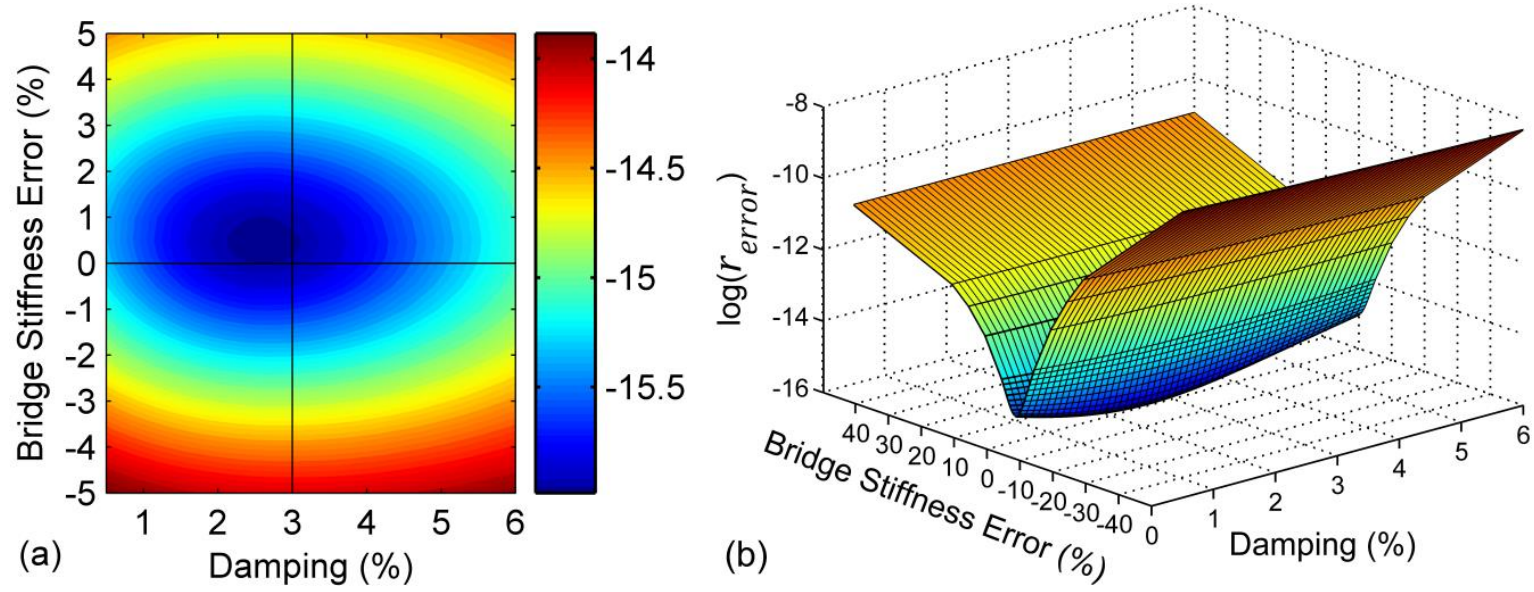

Fig. 15

(a) Contour plot and (b) Surface plot of the log of least squares error, $\log \left(r_{\text {error }}\right)$, varying bridge stiffness. Target damping ratio is $3 \%(-)$. Vehicle velocity is $20 \mathrm{~m} \mathrm{~s}^{-1}$. Bridge span is $15 \mathrm{~m}$.

Figs. 16 and 17 illustrate results for the other two bridge spans defined in Table 2. Here, the error function reaches a minimum for the true values of stiffness and damping (3\%), 
indicating that the identification algorithm has the potential to predict the bridge stiffness in addition to the bridge's damping ratio accurately.
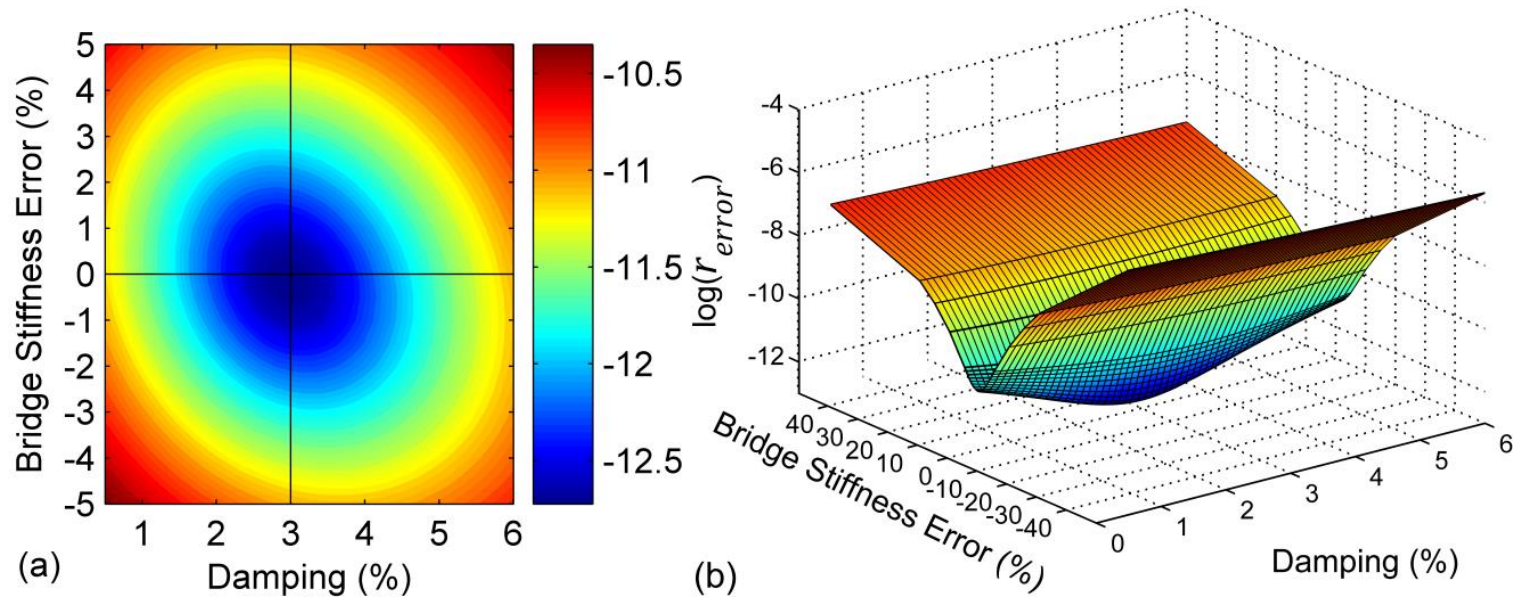

Fig. 16 (a) Contour plot and (b) Surface plot of the log of least squares error, $\log \left(r_{\text {error }}\right)$, varying bridge stiffness. Target damping ratio is $3 \%(-)$. Vehicle velocity is $20 \mathrm{~m} \mathrm{~s}^{-1}$. Bridge span is $25 \mathrm{~m}$.
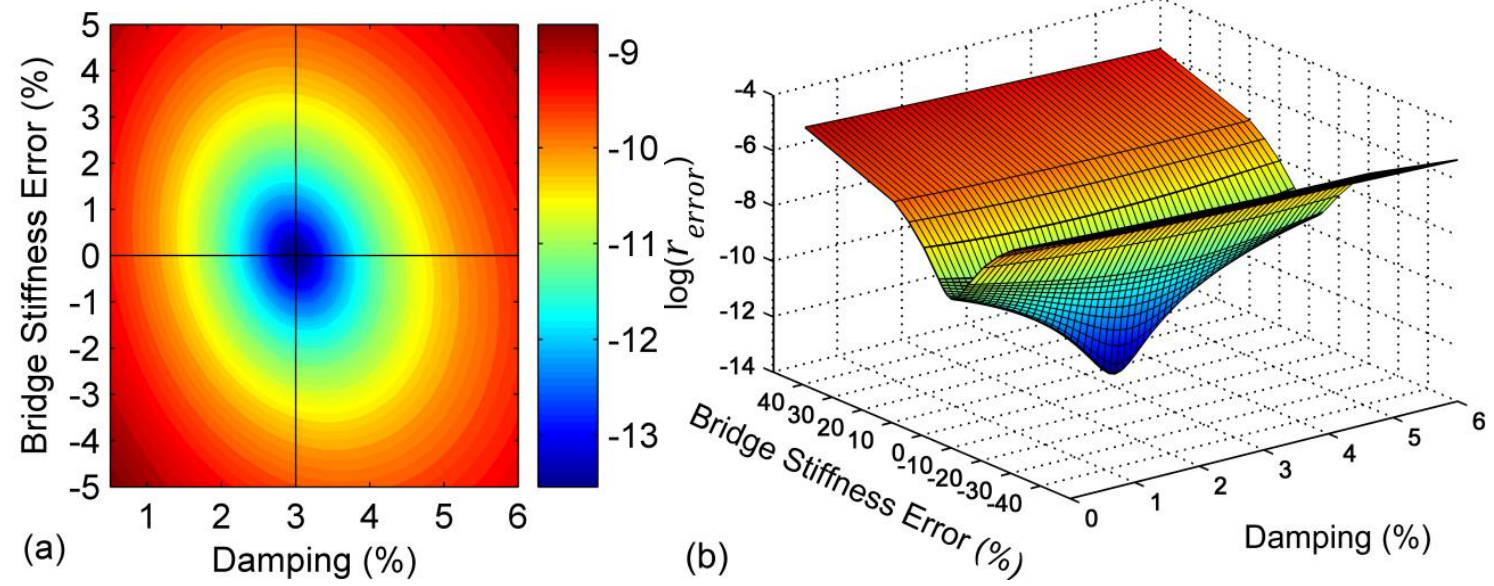

Fig. 17

(a) Contour plot and (b) Surface plot of the log of least squares error,

$\log \left(r_{\text {error }}\right)$, varying bridge stiffness. Target damping ratio is $3 \%(-)$. Vehicle velocity is $20 \mathrm{~m} \mathrm{~s}^{-1}$. Bridge span is $35 \mathrm{~m}$. 


\subsubsection{Vehicle suspension stiffness}

To investigate the effect of using incorrect vehicle model parameters in the damping identification algorithm, the suspension stiffness, $K_{1}$, used for the first axle of the vehicle model is varied. Fig. 18(a) shows a 2D contour plot of the log of the least squares error between road profile heights (Eq. (10)) for varying damping ratio and errors in suspension stiffness. As expected, the identification algorithm is more sensitive to errors in vehicle suspension parameters than to errors in damping (i.e., small changes in stiffness or damping lead to large or small changes in the objective function respectively). Similar to Figs. 15 to 17, Fig. 18(b) shows a 3D surface plot of the data in Fig. 18(a). This figure does not illustrate a difference between the least squares error obtained for an under- or over-estimation of the suspension stiffness as significant as for bridge stiffness in Section 4.7.1. In any case, a minimum can be found for an error of $+0.1 \%$ in stiffness and a damping ratio of $3.2 \%$, the accuracy being similar to those values obtained when optimising for incorrect values of bridge stiffness. Once again, similar results are obtained in simulations using other bridge spans and vehicle velocities. These results imply that, similar to errors in bridge stiffness, errors in the vehicle model suspension stiffness can be overcome by optimising over a wide range of values, where those values minimizing the error function can be used as reasonable estimators of suspension stiffness and damping ratio. 

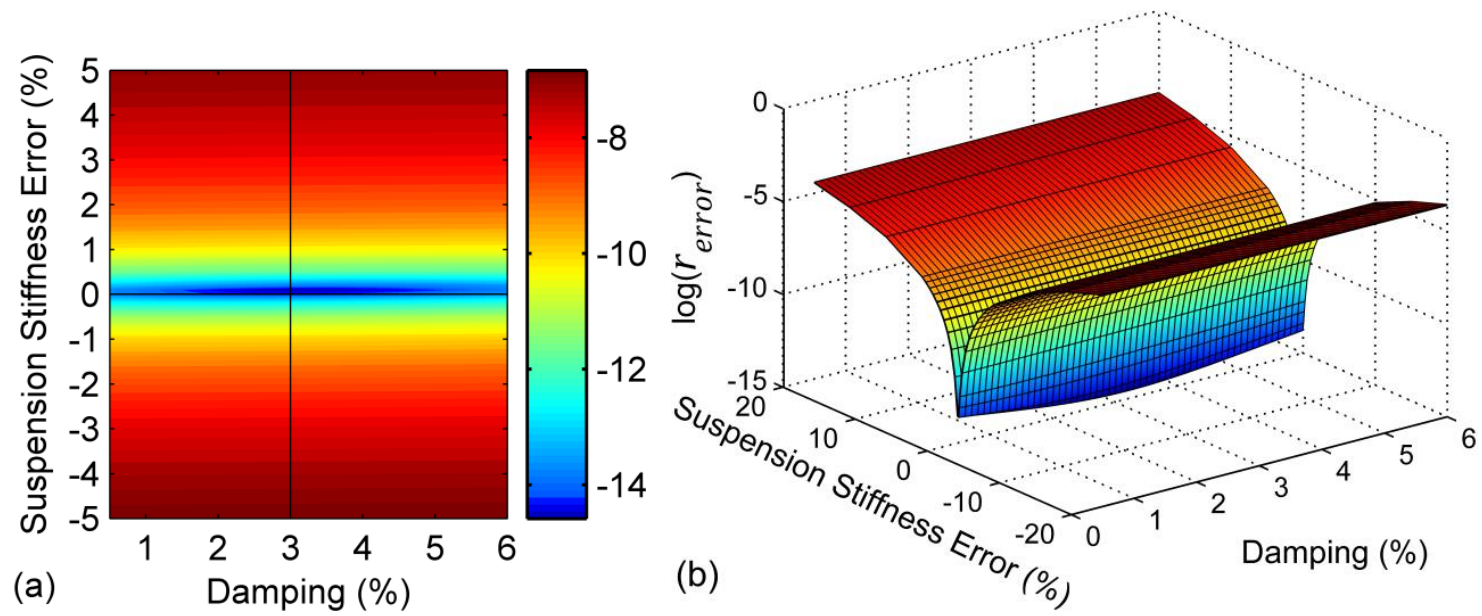

Fig. 18

(a) Contour plot and (b) Surface plot of the log of least squares error,

$\log \left(r_{\text {error }}\right)$, varying vehicle suspension stiffness. Target damping ratio is $3 \%$

(-). Vehicle velocity is $20 \mathrm{~m} \mathrm{~s}^{-1}$. Bridge span is $15 \mathrm{~m}$.

\subsection{The effect of a pothole and frequency matching}

The dynamic interaction between the vehicle and the bridge is a critical part of the damping identification algorithm. It follows that a change in this dynamic interaction, i.e., due to a deteriorated expansion joint prior to the bridge, will have an effect on the performance of the algorithm. To address this, simulations are carried out which incorporate a $0.02 \mathrm{~m}$ deep pothole in the road profile, corresponding to a deteriorated expansion joint. This pothole is modelled as a bump of a total width of $0.3 \mathrm{~m}$, as described by Cantero et al [40]: a $0.1 \mathrm{~m}$ length of gradual decrease down to $0.02 \mathrm{~m}$, a constant depression of $0.02 \mathrm{~m}$ for another $0.1 \mathrm{~m}$ and then, $0.1 \mathrm{~m}$ of an incremental increase in height until reaching the road level. It is located $0.5 \mathrm{~m}$ from the midpoint of the support bearing at the bridge entrance. In addition to this pothole, the properties of the vehicle are selected such that the bounce frequencies of the vehicle match the $1^{\text {st }}$ natural frequency of the bridge. Frequency matching has been highlighted as beneficial for the extraction of bridge dynamic parameters from the vehicle 
response as it increases the dynamic response of the bridge [27]. Therefore, it is expected that the existence of a pothole and frequency matching will improve the accuracy of the estimation of damping.

Fig. 19(a) shows a 2D contour plot of the log of the least squares error between road profile heights (Eq. (10)) for varying damping ratio and errors in the stiffness of the $15 \mathrm{~m}$ bridge model. The vehicle used to generate these results has its bounce frequency matched with the first natural frequency of the $15 \mathrm{~m}$ bridge, i.e., $5.66 \mathrm{~Hz}$. The properties of this vehicle are the same as those given in Table 1 , but the suspension stiffness, $K_{1}$ and $K_{2}$, which are increased to $7.96 \times 10^{6} \mathrm{~N} \mathrm{~m}^{-1}$ and $1.48 \times 10^{7} \mathrm{~N} \mathrm{~m}^{-1}$ respectively for the purposes of frequency matching. This figure illustrates that a clear minimum is obtained with $0 \%$ stiffness error at the true damping ratio of 3\%. Also, a 3D surface plot of the data in Fig. 19(a) is shown in Fig. 19(b), with bridge stiffness percentage errors included up to $\pm 20 \%$. Comparing Fig. 19 to Fig. 15 , it is clear that frequency matching and the inclusion of a pothole in the road profile significantly improve not only the accuracy of the damping identification but also the accuracy of the bridge stiffness associated to the minimum value of the error function. This improvement can be explained by the increase in bridge excitation caused by the large dynamic response of the vehicle induced by the pothole and the frequency matching between the vehicle and bridge. Therefore it can be concluded that overall, an increased excitation of the bridge response is beneficial for the successful identification of bridge parameters. 


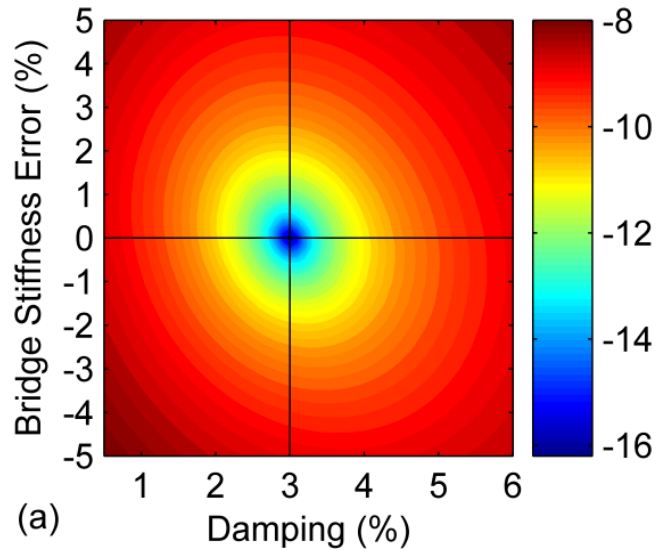

(a)

Fig. 19

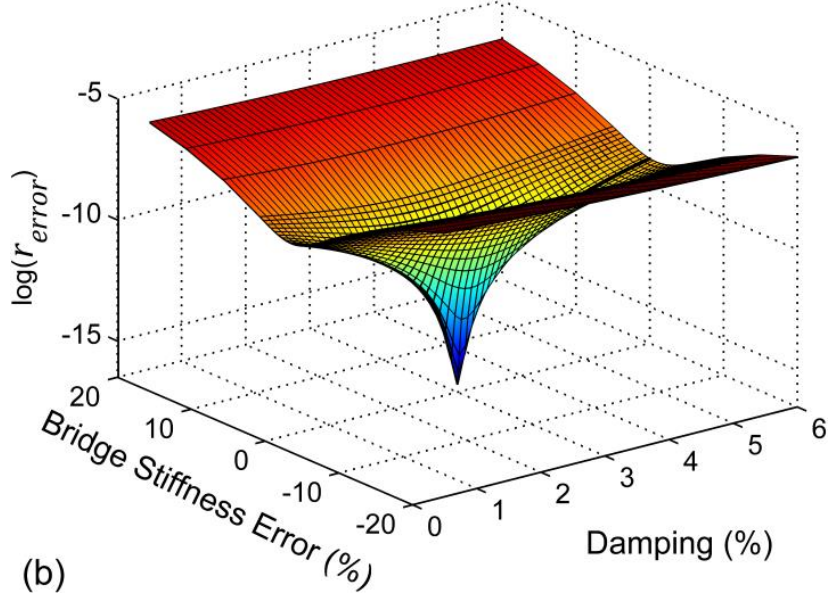

(b)

(a) Contour plot and (b) Surface plot of the log of least squares error, $\log \left(r_{\text {error }}\right)$, for frequency matched vehicle and pothole. Target damping ratio is $3 \%(-)$. Vehicle velocity is $20 \mathrm{~m} \mathrm{~s}^{-1}$. Bridge span is $15 \mathrm{~m}$.

\section{Conclusions}

This paper presents a novel method for the identification of the damping ratio of a bridge using acceleration measurements from a moving vehicle. The method is carried out in 6 sequential steps and numerically validated for a range of bridge spans, vehicle velocities and damping ratios. In the case of simulations for a class ' $A$ ' road profile, 21 vehicle velocities between $10 \mathrm{~m} \mathrm{~s}^{-1}$ and $30 \mathrm{~m} \mathrm{~s}^{-1}, 9$ levels of damping and noise free data, $88 \%$ of all simulations identified the correct damping ratio within a $10 \%$ margin of error. In addition, $40 \%$ of all simulations identified the correct value within a $1 \%$ margin of error. The method performs less accurately for shorter bridge spans and at certain vehicle velocities as a result of a low dynamic excitation of the bridge and the integration process respectively. There are a very small number of the bridge/velocity combinations which provide damping estimation error greater than $30 \%$. In practice, these outliers can be identified and overcome by carrying out multiple crossings of the bridge at more than one vehicle velocity. 
As past studies encountered difficulties with road profile roughness, the sensitivity of the method to road roughness has been analysed. Results for ISO class ' $A$ ' and class ' $C$ ' road profiles have exhibited similar levels of accuracy and this is highlighted as a big advantage of the method. For example, for a target damping value of $3 \%, 89 \%$ of simulations for both the class ' $\mathrm{A}$ ' and ' $\mathrm{C}$ ' road profiles identified the correct damping ratio within a $10 \%$ margin of error.

It has also been found that overall the method is not very sensitive to the addition of low levels of noise to the measured accelerations, except for the $15 \mathrm{~m}$ bridge at particular velocities which experienced an increase in average absolute percentage error from $8 \%$ for the noise-free damping estimates to $35 \%$ for the noise corrupted estimates. As the algorithm described in this paper requires the double integration of accelerations, the effect of an incorrect assumed value for the initial conditions of the vehicle degrees of freedom has been investigated. Given that the method calculates the damping based on the difference between the predictions of road irregularities between two axles, accuracy is not sensitive to the selected initial conditions provided a linear correction technique is applied.

A number of difficulties are expected in the field that will reduce the accuracy of the algorithm, i.e., deviations between mathematical models and reality. Inaccuracies in the assumed bridge or vehicle model have been addressed by varying the bridge stiffness and vehicle suspension stiffness respectively with respect to their true value. It has been found that neither affects the damping estimate significantly. Also, varying these stiffness values highlighted the potential of the proposed algorithm to identify not also damping but also other bridge parameters such as stiffness within a reasonable level of accuracy. 
Finally, a pothole has been incorporated in the road profile prior to the bridge to investigate its effect on the performance of the algorithm. A vehicle model has also been frequency matched with the $15 \mathrm{~m}$ bridge in simulations. It has been found that the increased excitation caused by the pothole and the resonance due to frequency matching improved the accuracy of the damping ratio estimate and the bridge stiffness estimate considerably, indicating that they could be beneficial for the implementation of this algorithm in practice. Overall, the positive results of the algorithm proposed in this theoretical investigation suggest that an instrumented vehicle has the potential to be implemented as a sensitive low-cost method of identifying bridge parameters such as damping and stiffness in short to medium span bridges.

\section{Acknowledgement}

The authors wish to express their gratitude for the financial support received from the 7 th European Framework ASSET (Advanced Safety and Driver Support in Efficient Road Transport) Project towards this investigation.

\section{References}

[1] C. Farrar, K. Worden, An introduction to structural health monitoring. Philosophical Transactions of the Royal Society A 365 (2007) 303-315.

[2] J.M.W. Brownjohn, Structural health monitoring of civil infrastructure. Philosophical Transactions of the Royal Society A 365 (2007) 589-622.

[3] P.C. Chang, A. Flatau, S.C. Liu, Review Paper: Health Monitoring of Civil Infrastructure. Structural Health Monitoring 2(3) (2003) 257-267. 
[4] S.W. Doebling, C.R. Farrar, M.B. Prime, D.W. Shevitz, Damage identification and health monitoring of structural and mechanical systems from changes in their vibration characteristics: A Literature Review. Los Alamos National Laboratory Report LA-13070MS, USA (1996).

[5] E.P. Carden, P. Fanning, Vibration based condition monitoring: A review. Structural Health Monitoring 3(4) (2004) 355-377.

[6] O.S. Salawu, Detection of structural damage through changes in frequency: A review. Engineering Structures 19(9) (1997) 718-723.

[7] H.W. Shih, D.P. Thambiratnam, T.H.T. Chan, Vibration based structural damage detection in flexural members using multi-criteria approach. Journal of Sound and Vibration 323 (2009) 645-661.

[8] R.O. Curadelli, J.D. Riera, D. Ambrosini, M.G., Amani, Damage detection by means of structural damping identification. Engineering Structures 30 (2008) 3497-3504.

[9] C. Modena, D. Sonda, D. Zonta, Damage Localization in a Reinforced Concrete Structures by Using Damping Measurements. Key Engineering Materials 167-168 (1999) $132-141$.

[10] Y.B. Yang, C.W. Lin, J.D. Yau, Extracting bridge frequencies from the dynamic response of a passing vehicle. Journal of Sound and Vibration 272 (2004) 471-493.

[11] Y. Oshima, T. Yamaguchi, Y. Kobayashi, K. Sugiura, Eigenfrequency estimation for bridges using the response of a passing vehicle with excitation system. Proceedings of the Fourth International Conference on Bridge Maintenance, Safety and Management, IABMAS2008, Seoul, Korea, 2008, 3030-3037.

[12] P.J. McGetrick, A. González, E.J. OBrien, Theoretical investigation of the use of a moving vehicle to identify bridge dynamic parameters. Insight 51(8) (2009) 433-438. 
[13] C.W. Lin, Y.B. Yang, Use of a passing vehicle to scan the fundamental bridge frequencies. An experimental verification. Engineering Structures 27 (2005), 1865-1878.

[14] Y.B. Yang, K.C. Chang, Extraction of bridge frequencies from the dynamic response of a passing vehicle enhanced by the EMD technique. Journal of Sound and Vibration 322 (2009) 718-739.

[15] A. González, E. Covián, J. Madera, Determination of Bridge Natural Frequencies Using a Moving Vehicle Instrumented with Accelerometers and GPS. Proceedings of the Ninth International Conference on Computational Structures Technology, Athens, Greece, 2008, paper 281 .

[16] C.W. Kim, M. Kawatani, Challenge for a Drive-by Bridge Inspection. Proceedings of the 10th International Conference on Structural Safety and Reliability, ICOSSAR2009, Osaka, Japan, 2009, 758-765.

[17] T. Toshinami, M. Kawatani, C.W. Kim, Feasibility investigation for identifying bridge's fundamental frequencies from vehicle vibrations. Proceedings of the Fifth International Conference on Bridge Maintenance, Safety and Management, IABMAS2010, Philadelphia, USA, 2010, 317-322.

[18] C. Williams, O.S. Salawu, Damping as a Damage Indication Parameter. Proceedings of the 15th International Modal Analysis Conference, Orlando, Florida, USA, 1997, 1531-1536. [19] H. Sohn, C.R. Farrar, F.M. Hemez, D.D. Shunk, D.W. Stinemates, B.R. Nadler. A review of structural health monitoring literature: 1996-2001. Los Alamos National Laboratory Report LA-13976-MS, USA (2003).

[20] G. Gutenbrunner, K. Savov, H. Wenzel, Sensitivity Studies on Damping Estimation. Proceedings of the Second International Conference on Experimental Vibration Analysis for Civil Engineering Structures (EVACES), Porto, Portugal, October 2007. 
[21] G. Kawiecki, Modal damping measurement for damage detection. Smart Materials and Structures 10(3) (2001) 466-471.

[22] A.P. Jeary, The description and measurement of non linear damping in structures. Journal of Wind Engineering and Industrial Aerodynamics 59 (1996) 103-114

[23] T.Y. Liu, W.L. Chiang, C.W. Chen, W.K. Hsu, L.C. Lu and T.J. Chu, Identification and monitoring of bridge health from ambient vibration data. Journal of Vibration and Control 17(4) (2011) 589-603.

[24] J. Chen, Y.L. Xu, R.C. Zhang, Modal parameter identification of Tsing Ma suspension bridge under Typhoon Victor: EMD-HT method. Journal of Wind Engineering and Industrial Aerodynamics 92 (2004) 805-827.

[25] Huang Fang-Lin, Xue-Min Wang, Zheng-Qing Chen, Xu-Hui He, Yi-Qing Ni, A new approach to identification of structural damping ratios. Journal of Sound and Vibration 303 (2007) 144-153.

[26] F. Magalhaes, A. Cunha, E. Caetano, R. Brincker, Damping estimation using free decays and ambient vibration tests. Mechanical Systems and Signal Processing 24 (2010) 12741290.

[27] A. González, E. OBrien, P. McGetrick, Detection of Bridge Dynamic Parameters Using an Instrumented Vehicle. Proceedings of the Fifth World Conference on Structural Control and Monitoring, Tokyo, Japan (2010), paper 34.

[28] MatLab. The MathWorks, Inc., MATLAB, Version 6, USA (2003). http://www.mathworks.com

[29] K. Henchi, M. Fafard, M. Talbot, G. Dhatt, An efficient algorithm for dynamic analysis of bridges under moving vehicles using a coupled modal and physical components approach. Journal of Sound and Vibration 212(4) (1998) 663-683. 
[30] G.H. Tan, G.H. Brameld, D.P. Thambiratnam, Development of an analytical model for treating bridge - vehicle interaction. Engineering Structures 20 (1- 2) (1998) 54 - 61.

[31] C.W. Kim, M. Kawatani, K.B. Kim, Three-dimensional dynamic analysis for bridgevehicle interaction with roadway roughness. Computers and Structures 83 (2005) 1627-1645. [32] N.K. Harris, E.J. OBrien, A. González, Reduction of bridge dynamic amplification through adjustment of vehicle suspension damping. Journal of Sound and Vibration 302 (2007) 471-485.

[33] D. Cantero, E.J. OBrien, A. González, Modelling the vehicle in vehicle infrastructure dynamic interaction studies. Proceedings of the Institution of Mechanical Engineers, Part K, Journal of Multi-body Dynamics 224(K2) (2010) 243-248.

[34] A. González, Vehicle-bridge dynamic interaction using finite element modelling. In: David Moratal (Ed.). Finite Element Analysis. Sciyo, Croatia, 637-662, 2010.

[35] C.W. Kim, M. Kawatani, Pseudo-static approach for damage identification of bridges based on coupling vibration with a moving vehicle. Structure and Infrastructure Engineering 4(5) (2008) 371-379.

[36] D. Cebon, Handbook of vehicle-road interaction. Swets and Zeitlinger Publishers, Lisse (1999).

[37] N. Harris, A. Gonzalez, E.J. OBrien, P. McGetrick, Characterisation of pavement profile heights using accelerometer readings and a combinatorial optimisation technique. Journal of Sound and Vibration 329 (2010) 497-508.

[38] M.I Friswell, J.E. Mottershead, Finite element model updating in structural dynamics, Springer, 1995, 286 pages.

[39] R.W. Clough, J. Penzien, Dynamics of structures, McGraw-Hill, 1993. 
[40] D. Cantero, A. Gonzalez, E.J. OBrien, Comparison of bridge dynamic amplification due to articulated 5-axle trucks and large cranes. Baltic Journal of Road and Bridge Engineering 6(1) (2011) 39-47.

[41] K.J. Bathe, E.L. Wilson, Numerical methods in finite element analysis. Prentice Hall, 1976.

[42] J.W. Tedesco, W.G. McDougal, C.A. Ross, Structural Dynamics, Theory and Applications. Addison-Wesley, 1999.

[43] W. Weaver, P.R. Johnston, Structural Dynamics by Finite Elements. Prentice-Hall, 1987.

[44] ISO 8608:1995, Mechanical vibration-road surface profiles-reporting of measured data', International Standards Organisation (1995).

[45] K.-T. Park, S.-H. Kim, H.-S. Park, K.-W. Lee, The determination of bridge displacement using measured acceleration. Engineering Structures 27 (2005) 371-378.

[46] A.D. Dimarogonas, Vibration of cracked structures-a state of the art review. Engineering Fracture Mechanics 55(5) (1996) 831-857.

[47] J.G. MacGregor, J.K. Wight, Reinforced Concrete: Mechanics and Design - 4th Edition in SI Units. Prentice Hall, 2006. 